\title{
Review Article \\ Systematic Review on Acupuncture for Treatment of Dysphagia after Stroke
}

\author{
Qiuping Ye, ${ }^{1}$ Yu Xie, ${ }^{2}$ Junheng Shi, ${ }^{1} \mathrm{Zhenhua} \mathrm{Xu}^{2}$ Aihua Ou, ${ }^{2}$ and Nenggui $X u^{1}$ \\ ${ }^{1}$ Guangzhou University of Chinese Medicine, Airport Road, Baiyun District, Guangdong, Guangzhou 510006, China \\ ${ }^{2}$ Guangdong Provincial Hospital of Chinese Medicine, Yide Road, Yuexiu District, Guangdong, Guangzhou 510006, China \\ Correspondence should be addressed to Zhenhua Xu; xzh197011@163.com
}

Received 3 March 2017; Revised 11 June 2017; Accepted 18 June 2017; Published 9 August 2017

Academic Editor: Ching-Liang Hsieh

Copyright ( 2017 Qiuping Ye et al. This is an open access article distributed under the Creative Commons Attribution License, which permits unrestricted use, distribution, and reproduction in any medium, provided the original work is properly cited.

\begin{abstract}
Objective. To assess the therapeutic efficacy of acupuncture for dysphagia after stroke. Methods. Seven electronic databases were searched from their inception until 31 September 2016. All randomized controlled trials (RCTs) incorporating acupuncture or acupuncture combined with other interventions for treatment of dysphagia after stroke were enrolled. Then they were extracted and assessed by two independent evaluators. Direct comparisons were conducted in RevMan 5.3.0 software. Results. 6010 patients of 71 papers were included. The pooled analysis of efficacy rate of 58 studies indicated that acupuncture group was superior to the control group with moderate heterogeneity ( $\mathrm{RR}=1.17,95 \% \mathrm{CI}: 1.131 .21, Z=9.08$, and $P<0.00001)$; meta-analysis of the studies using blind method showed that the efficacy rate of acupuncture group was 3.01 times that of control group with no heterogeneity $(\mathrm{RR}=3.01,95 \% \mathrm{CI}: 1.954 .65, Z=4.97$, and $P<0.00001)$. Only 13 studies mentioned the safety evaluation. Conclusion. The result showed that the acupuncture group was better than control group in terms of efficacy rate of dysphagia after stroke. And the combining result of those researches using blind method was more strong in proof. Strict evaluation standard and high-quality RCT design are necessary for further exploration.
\end{abstract}

\section{Introduction}

Dysphagia was one of the most common sequelae after stroke. The incidence reached $81 \%$ [1]. There were many complications in dysphagia, such as cacotrophy [2], dehydration, aspiration, and pneumonia [3]. Those complications improve the morbidity, mortality, the rehabilitation, and the quality of life of the patients. So the medication and intervention time are very important for recovery. Acupuncture was an effective method and more and more welcomed and applied clinically [4]. There were many studies [5-7] about the acupuncture for treatment of dysphagia after stroke internationally, including the scalp acupuncture, nape needle, auricular needling, or combing with other methods.

Though, there were some systematic reviews focusing on the acupuncture for treatment of dysphagia in stroke. There was lack of higher quality research or the positive conclusion could not be obtained. Thus, the inclusion and exclusion criteria were formulated after integrating the previous relevant reports. And the studies using single blind method were pooled to be analysed alone.

\section{Method and Data}

The criterion of systematic review was published in the Cochrane Collaboration which was available on http://handbook.cochrane.org/.

2.1. Type of Studies. All articles were included that reported an RCT in patients with dysphagia after stoke. And the animal experiments were not inclusive.

2.2. Participants. All the patients should conform to the explicit clinical diagnosis criteria of stroke and dysphagia. They should meet the following diagnosis of stroke: (1) the diagnostic criterion of the Fourth National Conference on cerebrovascular diseases in 1994 or the revised diagnostic criterion in 1995 or 1996; (2) the revised "Various Types of Cerebrovascular Disease Diagnosis Points" of The Fourth National Conference on cerebrovascular diseases of Chinese Medicine Association; (3) the "Chinese Cerebrovascular Disease Prevention And Treatment Guidelines (Try Out)" established by Neurology Branch of Chinese Medical Association 
TABLE 1: Retrieved literatures.

\begin{tabular}{lcccccccc}
\hline Database & CNKI & WanFang & CSJD & CBM & PubMed & EMBASE & Cochrane & SCI \\
\hline Number & 1361 & 1451 & 593 & 388 & 41 & 0 & 2 & 13 \\
\hline
\end{tabular}

according to the 2005 or 2007 Disease Control Division; (4) 1996 Chinese Medicine Internal Medicine Association "criterion for evaluating curative effect of apoplexy"; (5) the guidelines for diagnosis and treatment of acute ischemic stroke composed by cerebrovascular branch of Neurology of Chinese Medical Association; (6) the guidelines for diagnosis and treatment of acute ischemic stroke in China 2010 Edition; (7) National Institutes of Health Stroke Scale (NIHSS) $[8,9] ;(8)$ the therapeutic efficacy evaluation standard of TCM diagnosis for stroke; (9) confirmed by head CT or MRI and other imaging methods for stroke; (10) Summary of the Sixth National Conference on cerebrovascular diseases.

2.3. Interventions. For the intervention in acupuncture group, acupuncture alone or combined with other interventions was all included, such as the rehabilitation training, swallowing therapeutic apparatus, swallowing training, and electrical stimulation. There was no distinction for the acupuncture manipulation, acupoint, stimulation intensity, and course of treatment. It is available for blank control group, drugs, or rehabilitation training in control group.

2.4. Outcome Measurement. The clinical symptoms had obviously improved with specific evaluation criteria such as the (1) Watian Swallowing Test (WST) [10]; (2) Standardized Swallowing Assessment (SSA) [11]; (3) Ichiro Fujishima Rating Scale (IFRS) [12]; (4) Caiteng 7 Rank for dysphagia [13] or with using the objective index as the efficacy evaluation criterion, such as (1) video-fluoroscopic swallowing study [14]; (2) endoscopic evaluation of swallowing [15]; (3) fluorescence barium swallowing radiography score [16] which were recognized as swallowing assessment.

2.5. Information Sources and Search Strategy. We search the following electronic databases from their inception until September 30, 2016: Science Citation Index (SCI), Plumbed, The Cochrane Library, EMBASE, Chinese National Knowledge Infrastructure (CNKI), WanFang Database, Chinese Scientific Journals Database (CSJD), and Chinese Biomedical Literature Database (CBM). The searching terms include "stroke", "apoplexy", "cerebral hemorrhage", "acicula", "acupuncture", "impaired swallowing”, and "dysphagia”.

2.6. Data Extraction. Data were extracted independently by two authors (Qiuping Ye and Yu Xie) using a specifically designed data extracted form. The disagreements were solved by the third author's assistance (Junheng Shi) if necessary. The following information was extracted: (1) the first author, year of publication and the journal; (2) the research design; (3) the basic situation of the patients; (4) the inclusion and exclusion criteria; (5) the indicators of evaluation; and so on. After recording the reasons for exclusion, we got the flow diagram (see Table 1 and Figure 1) including 71 studies [1787].

2.7. Quality Assessment. The methodological quality of each study was assessed from the following aspects: (1) random sequence generation; (2) allocation concealment; (3) blinding of participants and personnel; (4) blinding of outcome assessment; (5) incomplete outcome data; (6) selective reporting; (7) other bias and judging from "yes (low risk)," "no (high risk)," or "unclear (information is insufficient to evaluate)" and reporting the risk of bias graph (Figures 2 and 3).

\section{Result}

71 studies including 6010 patients were enrolled finally. There were 2991 participants in acupuncture group and 3019 participants in control group.

3.1. The Basic Characteristics. Two groups were compared statistically based on age, gender, duration, and degree of dysphagia. And the baseline was comparable. See Table 2; 12 studies used the complete random and allocation concealment; 10 studies used the single blind method in the outcome assessment and statistics analysis. For the incomplete outcome data, 12 studies reported the fall off and exit of patients without any effect on the result; 17 studies mentioned the funding support, and not the others.

3.2. Data Analysis. RevMan 5.3.0 software was used for data analysis. And the different outcome assessment indicators were used to be classified and analysed. They were presented as risk ratio $(\mathrm{RR})$ or mean difference (MD) with a $95 \%$ confidence interval.

3.3. Efficacy Rate. 62 studies used the clinical efficacy rate as the evaluation indicator with the dichotomous data. So the risk ratio $(\mathrm{RR})$ was used to show the result. We found the medium heterogeneity $\left(I^{2}=68 \%\right)$ after combining data. We could observe from the funnel plot that 3 studies [19, 31, 82] had deviated from the center line. After sensitivity analysis, we found that one study [19] considered the significantly effective result as recovery and the other as invalidation, which led to difference in results. At the same time, the intervention group of the two studies [31, 82] was treated with acupuncture combined with western medicine. And the curative effect was significantly higher than that of the control group. All the dots were equally distributed on both sides of the dashed line in the funnel plot with no publication bias after removing them (Figure 4). The moderate heterogeneity was found after remerging $\left(I^{2}=58 \%\right)$. So we chose the random effect model (Figure 5). The pooled analysis showed that the total rectangle was on the right of the equivalent line, which indicated the curative effect of acupuncture group was 


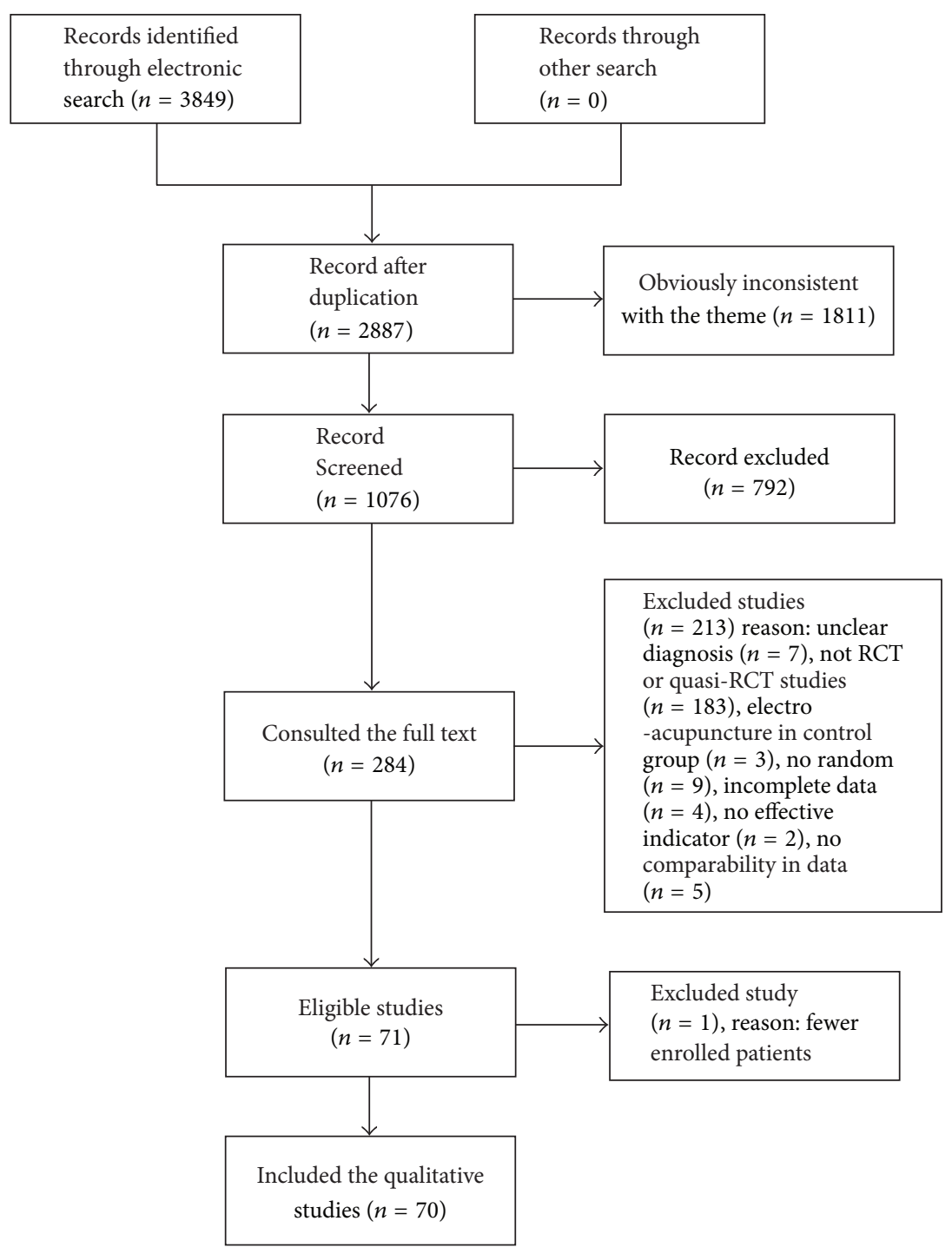

FIgURE 1: The screening flow diagram.

better than the control group $(\mathrm{RR}=1.17,95 \% \mathrm{CI}: 1.131 .21$, $Z=9.08$, and $P<0.00001)$.

3.4. Standard Swallowing Assessment (SSA). There were 11 studies that used the SSA as the effective evaluation standard with the continuous data. The meta-analysis of them was showed in mean difference with high heterogeneity $\left(I^{2}=\right.$ $83 \%$ ). So the random effect model was used (Figure 6). The figure showed that acupuncture group could lower the SSA cores $(\mathrm{MD}=3.7,95 \% \mathrm{CI}:-4.93-2.48, Z=5.94$, and $P<$ $0.00001)$.

3.5. Watian Swallowing Test. The Watian Swallowing Test was used in 24 studies; 9 of them used the dichotomous data. The risk ratio was selected to demonstrate the count data. The results (Figure 7 ) showed high heterogeneity $\left(I^{2}=87 \%\right)$. Hence the random effect model was used. And the rectangle was on the right of the equivalent line, which indicated that acupuncture group could improve the efficacy of dysphagia after stroke $(\mathrm{RR}=1.25,95 \% \mathrm{CI}: 1.031 .50, Z=2.31$, and $P=0.02<0.05)$.

15 studies used the continuous data. And the mean difference was applied. The results showed that the heterogeneity of the merger was large. So we did the subgroup analysis according to the course of disease. Then the heterogeneity decreased from $95 \%$ to $67.4 \%$ (Figure 8 ). There was no publication bias in the funnel plot (Figure 9). Meanwhile, the pooled analysis showed that the acupuncture could lower the Watian Swallowing Test score $(\mathrm{MD}=0.97,95 \% \mathrm{CI}:-1.11-0.47$, $Z=4.82$, and $P<0.00001)$.

3.6. Swallowing Functional Assessment. Among the included studies, 8 of them used the Swallowing Functional Assessment to evaluate the effectiveness of treatment with the continuous data. The result (Figure 10) exhibited the medium heterogeneity $\left(I^{2}=65 \%\right)$ with mean difference (MD). The result explained that acupuncture could improve the 


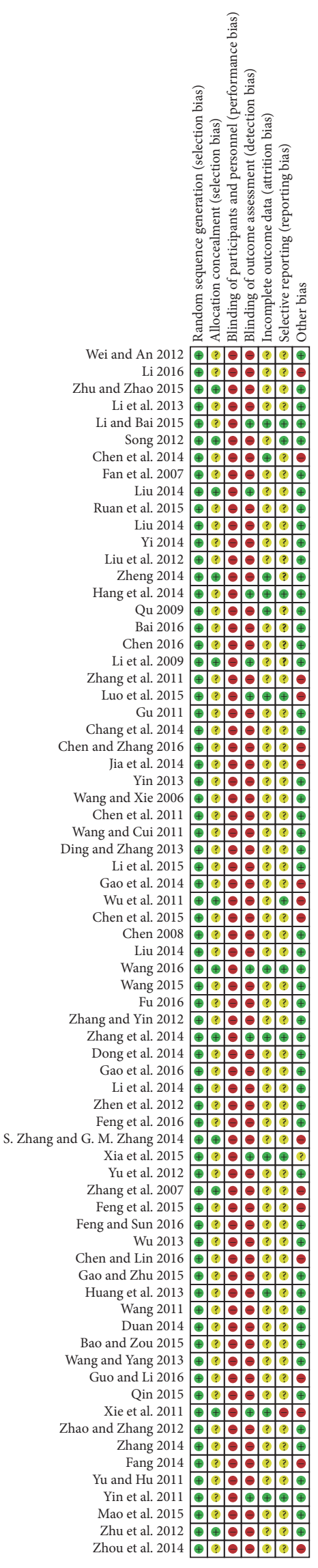

FIgURE 2: The bias of each study. swallowing function with the random effect model ( $\mathrm{MD}=$ 1.48, 95\% CI: $1.181 .79, Z=9.59$, and $P<0.0001$ ).

3.7. Swallowing Disorder Integral. 5 studies selected the swallowing disorder scoring as evaluated standard. The metaanalysis of the 5 dichotomous data sets showed that the heterogeneity decreased from $85 \%$ to $40 \%$ after removing one study [59]. The sensitivity analysis indicated that the heterogeneity might be the treatment course of this study which was longer than the others. We could see from the figure that the score of the control group was higher than the acupuncture group (Figure 11). It illustrated that acupuncture group was able to lower the swallowing disorder integral (MD $=-0.71,95 \%$ CI: $-1.08-0.33, Z=3.7$, and $P=0.0002$ ).

3.8. Swallowing-Related Quality of Life (SWAL-QOL). 5 studies used the SWAL-QOL to express the Swallowing-Related Quality of Life before and after treatment. They all used the continuous data and mean difference to exhibit the results. The pooled analysis showed that rectangle was intersected with the equivalent line with high heterogeneity $\left(I^{2}=100 \%\right)$, which means nothing (Figure 12).

3.9. Activities of Daily Living (ADL). 2 studies [67, 78] used ADL to express the curative effect, two $[27,45]$ used the Barthel index, and the other one [54] used modified Barthel index. Among them, the activities of daily living before and after treatment were showed using the continuous data and mean difference. The meta-analysis indicted that acupuncture group obviously improved the activities of daily living of the patients with lower heterogeneity $\left(I^{2}=22 \%\right)$ (Figure 13). And it was 7.31 times as much as the control group $(\mathrm{MD}=7.46,95 \% \mathrm{CI}: 5.49$ 9.47, $Z=7.31$, and $P<0.0001)$.

3.10. Caiteng 7 Rank (CT7R). The CT7R was used in 2 studies $[48,87]$ with dichotomous and risk ratio. There was no heterogeneity $\left(I^{2}=0 \%\right)$ after combining the data with the fixed effect model (Figure 14), which indicated that the Caiteng 7 Rank scores of the acupuncture group were higher than the control group ( $\mathrm{RR}=1.22,95 \% \mathrm{CI}: 1.041 .42, Z=2.49$, and $P=0.01$ ).

The pooled analysis (Figure 15) of the 2 studies [44, 56] using Ichiro Fujishima Rating Scale (IFRS) showed no meaning with medium heterogeneity $\left(I^{2}=69 \%\right)$, neither the result of 2 studies $[17,45]$ using mini-nutritional assessment (MNA). Only one study [54] used Hamilton Depression Scale (HAMD), which showed that the depression degree of acupuncture group was lighter than the control group.

3.11. Blind Method Analysis. We extracted 7 studies using blind method from the enrolled studies, among which 4 studies used the clinical therapeutic efficiency and 5 used Watian Swallowing Test efficacy rate. There was no heterogeneity $\left(I^{2}=0 \%\right)$ after pooling them with dichotomous data and risk ratio (RR) (Figure 16). So the fixed effect model was used. The rectangle was on the right of equivalent line and the therapeutic efficiency of acupuncture group was 3.01 times 


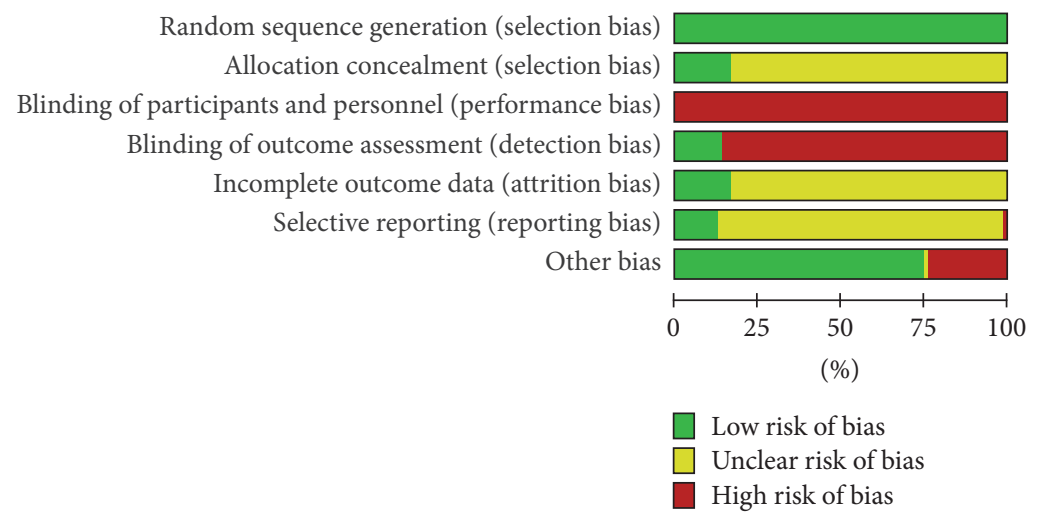

FIGURE 3: The summary of bias evaluation for the studies.

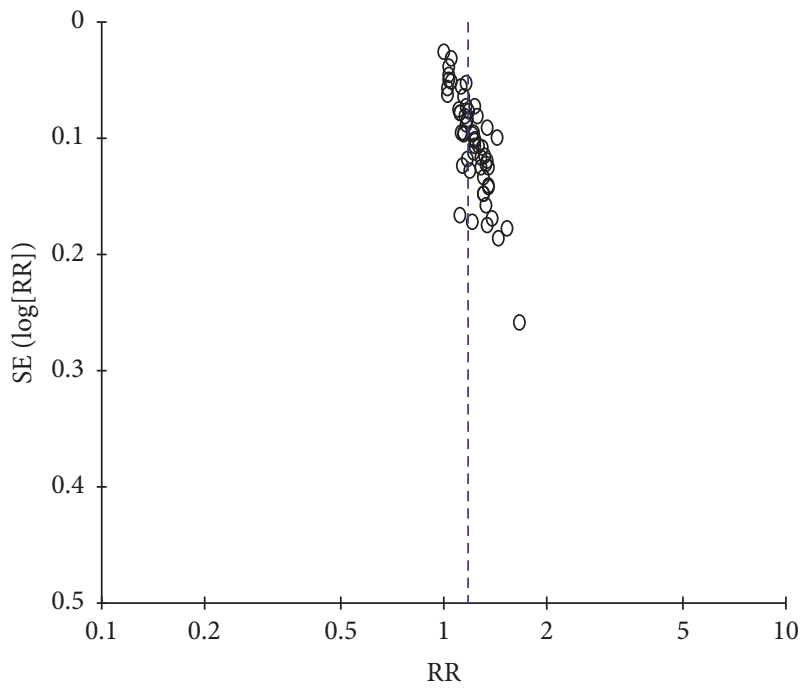

FIgURE 4: The funnel plot of clinical efficacy rate.

as much as the control group. The result indicated that the acupuncture group could improve the therapeutic efficiency of dysphagia after stroke ( $\mathrm{RR}=3.01,95 \% \mathrm{CI}$ : $1.954 .65, Z=$ 4.97, and $P<0.00001)$.

Among the studies employing blind method, 4 of them used the SSA as the assessment indicator with continuous data and mean difference (MD). High heterogeneity was found after combined analysis. Sensitivity analysis revealed that heterogeneity might be due to the use of the test method and the gender imbalance in the clinical cases from one study [17]. The heterogeneity was lower $\left(I^{2}=21 \%\right)$ after removing it. We could see from the figure (Figure 17) that the rectangle was on the left of equivalent line, with a trend that acupuncture group could lower the SSA scores $(\mathrm{MD}=-4.47$, 95\% CI: $-6.59-3.36, Z=7.85$, and $P<0.00001)$.

3.12. Adverse Reactions Report. Only 13 studies mentioned the security index, including how to prevent the subcutaneous hemorrhage, needle sickness, curved needle, broken needle, and the handing method during acupuncture process.
Meanwhile, some studies reported the influence caused by the adverse reactions, not the others.

\section{Discussion}

The study indicated that the therapeutic efficacy of acupuncture or acupuncture combined with other intervention was better than the control group, though some pooled results had higher heterogeneity. The interventions such as the acupuncture, rehabilitation training, and swallowing training were related to the professional skill of the practitioners, the same as the efficacy evaluation. Meanwhile, the various source of cases might lead to difference statistic results.

4.1. Comparison with Other Literatures. The acupuncture alone or combined with other interventions is widely used for dysphagia after stroke in China. There exists some evidence about the acupuncture for dysphagia after stoke. One report [88] stated although acupuncture had a tendency to improve dysphagia after stroke, it could not get the positive conclusion. There was report [89] which indicated that acupuncture combined with the swallowing rehabilitation training had certain advantage. Long and $\mathrm{Wu}$ [90] pointed out that acupuncture may be benefit for dysphagia, but highquality research was needed. The present study reworked out inclusion and exclusion criteria to evaluate the efficacy of acupuncture for treatment of dysphagia after stroke and showed stronger evidence in the result.

4.2. Strengths and Limitations. In this paper, the studies included single blind method pooled to analysis alone and showed stronger evidence on acupuncture for treatment of dysphagia after stroke. We incorporated all researches in the past 5 years. Considering the clinical application of the intervention in this paper was special, such as the feeling of the patient. It was difficult to achieve true double blind. The studies using single blind method achieved the blind method to some extent. There was no or lower heterogeneity after combining. 


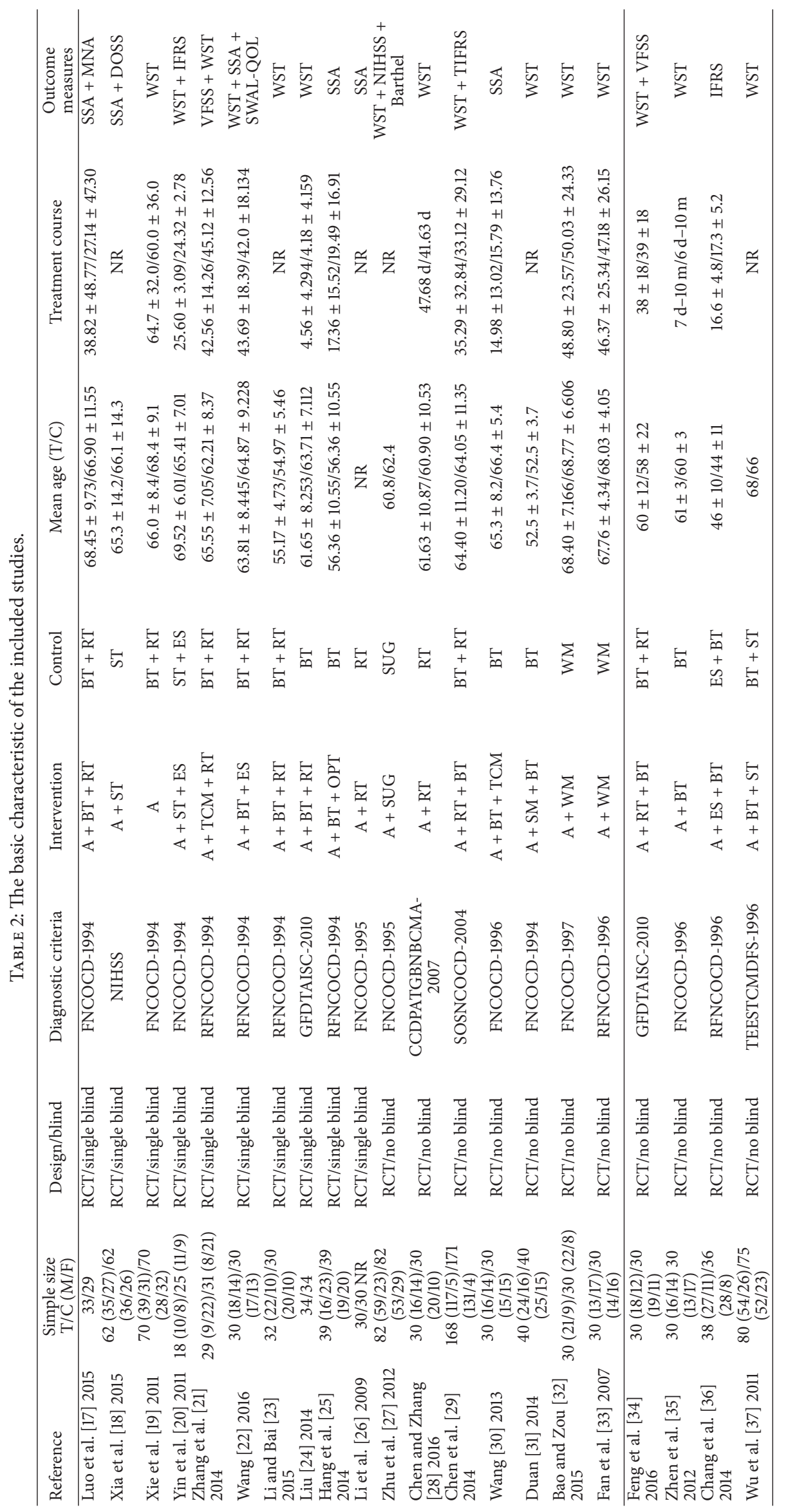




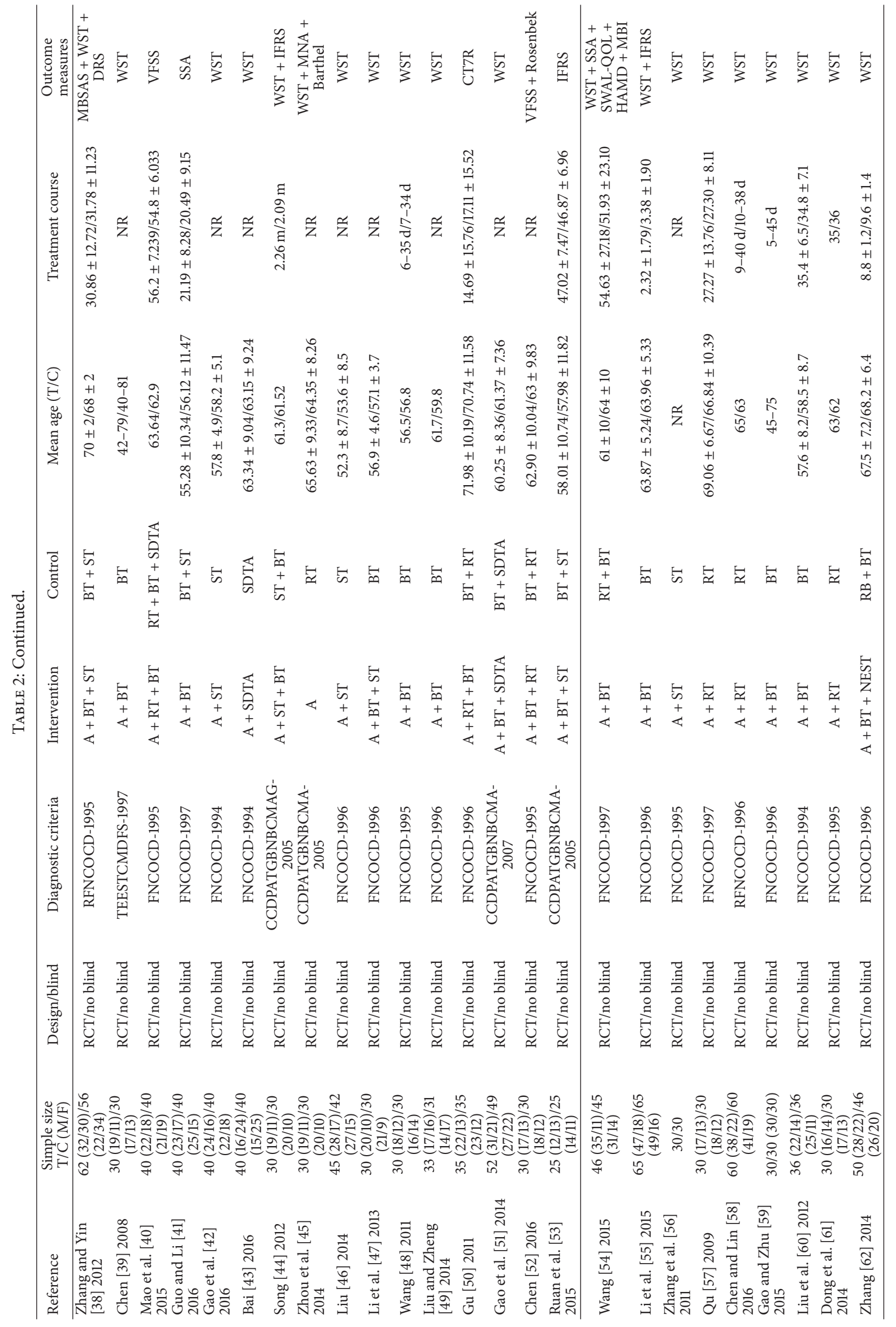




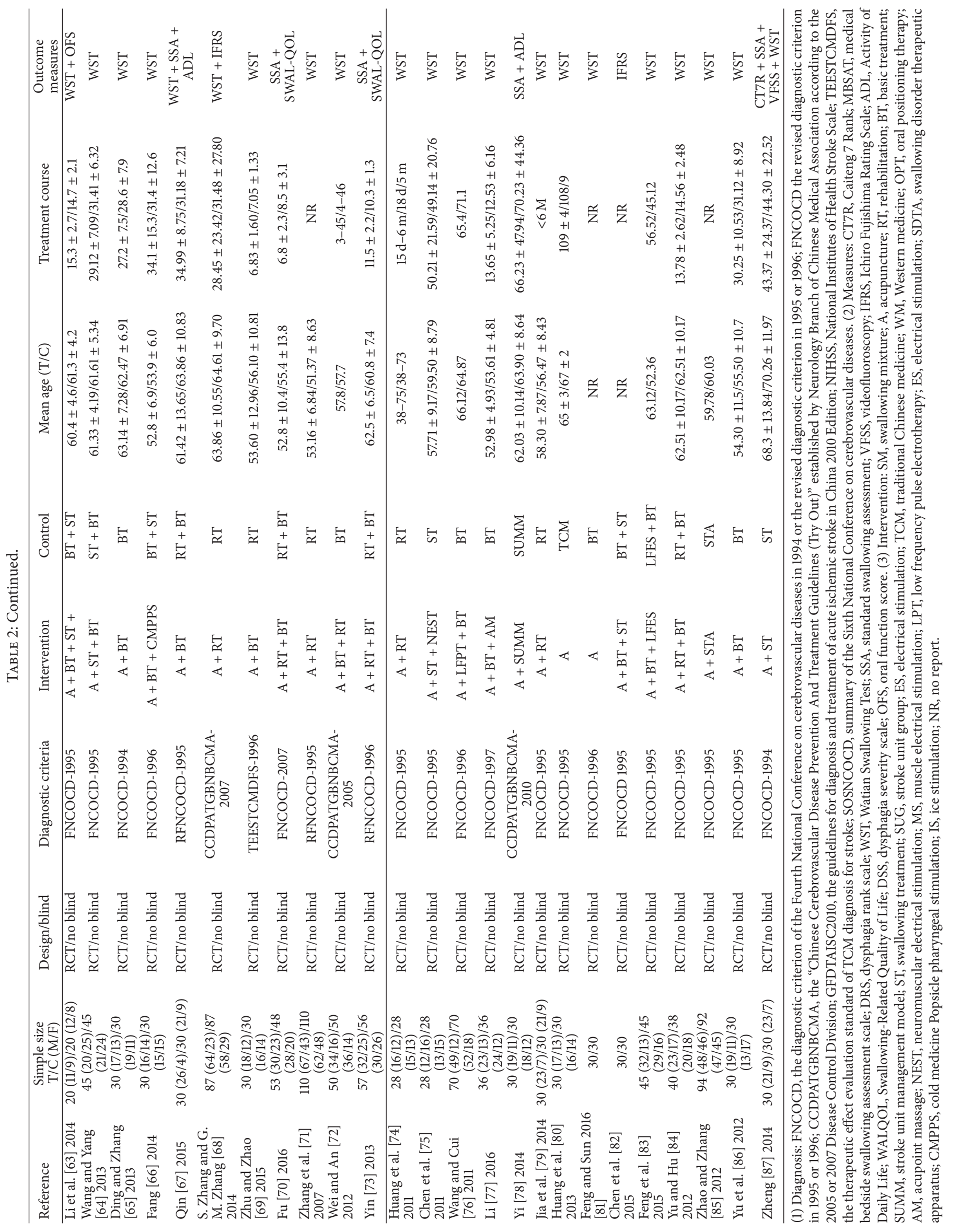




\begin{tabular}{|c|c|c|c|c|c|c|c|c|c|}
\hline \multirow{2}{*}{ Study or subgroup } & \multicolumn{2}{|c|}{ Experimental } & \multicolumn{2}{|c|}{ Control } & \multirow{2}{*}{ Weight } & \multirow{2}{*}{$\begin{array}{c}\text { Risk ratio } \\
\mathrm{M}-\mathrm{H} \text {, random, } 95 \% \mathrm{CI}\end{array}$} & \multirow{2}{*}{\multicolumn{3}{|c|}{$\begin{array}{c}\text { Risk ratio } \\
\mathrm{M}-\mathrm{H} \text {, random, } 95 \% \text { CI }\end{array}$}} \\
\hline & Events & Total & Events & Total & & & & & \\
\hline Wei and An 2012 & 46 & 50 & 40 & 50 & $2.1 \%$ & $1.15[0.98,1.35]$ & & - & \\
\hline Li 2016 & 33 & 36 & 29 & 36 & $1.8 \%$ & $1.14[0.94,1.37]$ & & $\leftarrow$ & \\
\hline Zhu and Zhao 2015 & 25 & 30 & 18 & 30 & $0.8 \%$ & $1.39[1.00,1.94]$ & & 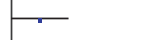 & \\
\hline Li et al. 2013 & 29 & 30 & 26 & 30 & $2.2 \%$ & $1.12[0.95,1.30]$ & & - & \\
\hline Li and Bai 2015 & 27 & 32 & 19 & 30 & $0.9 \%$ & $1.33[0.98,1.82]$ & & - & \\
\hline Song 2012 & 26 & 30 & 20 & 30 & $1.0 \%$ & $1.30[0.97,1.74]$ & & 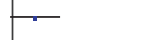 & \\
\hline Chen et al. 2014 & 159 & 168 & 154 & 171 & $3.4 \%$ & $1.05[0.99,1.12]$ & & + & \\
\hline Fan et al. 2007 & 26 & 30 & 9 & 30 & $0.0 \%$ & $2.89[1.64,5.08]$ & & & \\
\hline Liu 2014 & 30 & 34 & 23 & 34 & $1.2 \%$ & $1.30[1.00,1.70]$ & & - & \\
\hline Ruan et al. 2015 & 24 & 25 & 21 & 25 & $1.8 \%$ & $1.14[0.95,1.38]$ & & - & \\
\hline Liu 2014 & 42 & 45 & 32 & 42 & $1.8 \%$ & $1.23[1.02,1.48]$ & & - & \\
\hline Yi 2014 & 26 & 30 & 23 & 30 & $1.3 \%$ & $1.13[0.89,1.44]$ & & - & \\
\hline Liu et al. 2012 & 29 & 36 & 19 & 36 & $0.8 \%$ & $1.53[1.08,2.16]$ & & $\longrightarrow$ & \\
\hline Bai 2016 & 40 & 40 & 35 & 40 & $2.6 \%$ & $1.14[1.01,1.29]$ & & + & \\
\hline Chen 2016 & 29 & 30 & 26 & 30 & $2.2 \%$ & $1.12[0.95,1.30]$ & & + & \\
\hline Li et al. 2009 & 24 & 30 & 18 & 30 & $0.8 \%$ & $1.33[0.95,1.88]$ & & 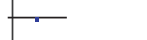 & \\
\hline Zhang et al. 2011 & 20 & 30 & 12 & 30 & $0.4 \%$ & $1.67[1.00,2.76]$ & & & \\
\hline Gu 2011 & 34 & 35 & 33 & 35 & $2.9 \%$ & $1.03[0.93,1.14]$ & & 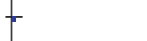 & \\
\hline Chang et al. 2014 & 38 & 38 & 36 & 36 & $3.5 \%$ & $1.00[0.95,1.05]$ & & 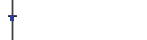 & \\
\hline Chen and Zhang 2016 & 30 & 30 & 29 & 30 & $3.0 \%$ & $1.03[0.94,1.13]$ & & 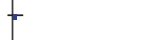 & \\
\hline Jia et al. 2014 & 29 & 30 & 23 & 30 & $1.6 \%$ & $1.26[1.02,1.55]$ & & 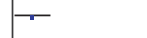 & \\
\hline Yin 2013 & 49 & 57 & 39 & 56 & $1.7 \%$ & $1.23[1.01,1.51]$ & & - & \\
\hline Huang 2011 & 27 & 28 & 20 & 28 & $1.3 \%$ & $1.35[1.06,1.72]$ & & $\longrightarrow$ & \\
\hline Chen et al. 2011 & 23 & 28 & 16 & 28 & $0.7 \%$ & $1.44[1.00,2.07]$ & & 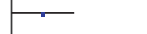 & \\
\hline Wang and Cui 2011 & 63 & 70 & 44 & 70 & $1.7 \%$ & $1.43[1.18,1.74]$ & & - & \\
\hline Li et al. 2015 & 60 & 65 & 48 & 65 & $2.1 \%$ & $1.25[1.06,1.47]$ & & - & \\
\hline Gao et al. 2014 & 48 & 52 & 44 & 49 & $2.6 \%$ & $1.03[0.91,1.16]$ & & $t$ & \\
\hline Wu et al. 2011 & 67 & 75 & 50 & 75 & $1.9 \%$ & $1.34[1.12,1.60]$ & & - & \\
\hline Liu 2014 & 31 & 33 & 22 & 31 & $1.3 \%$ & $1.32[1.04,1.68]$ & & - & \\
\hline Wang 2016 & 28 & 32 & 22 & 30 & $1.3 \%$ & $1.19[0.93,1.54]$ & & 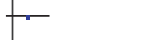 & \\
\hline Wang 2015 & 43 & 46 & 36 & 45 & $2.0 \%$ & $1.17[0.99,1.38]$ & & F- & \\
\hline Fu 2016 & 47 & 53 & 33 & 48 & $1.6 \%$ & $1.29[1.04,1.60]$ & & - & \\
\hline Zhang and Yin 2012 & 60 & 62 & 44 & 56 & $2.3 \%$ & $1.23[1.07,1.42]$ & & - & \\
\hline Zhang et al. 2014 & 30 & 31 & 21 & 29 & $1.4 \%$ & $1.34[1.06,1.69]$ & & - & \\
\hline Dong et al. 2014 & 27 & 30 & 20 & 30 & $1.1 \%$ & $1.35[1.02,1.79]$ & & 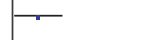 & \\
\hline Gao et al. 2016 & 39 & 40 & 37 & 40 & $2.9 \%$ & $1.05[0.95,1.17]$ & & + & \\
\hline Zhen et al. 2012 & 29 & 30 & 24 & 30 & $1.8 \%$ & $1.21[1.00,1.46]$ & & 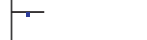 & \\
\hline Feng et al. 2016 & 26 & 30 & 20 & 30 & $1.0 \%$ & $1.30[0.97,1.74]$ & & + & \\
\hline S. Zhang and G. M. Zhang 2014 & 83 & 87 & 80 & 87 & $3.2 \%$ & $1.04[0.96,1.12]$ & & 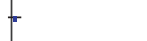 & \\
\hline Yu et al. 2012 & 28 & 30 & 23 & 30 & $1.5 \%$ & $1.22[0.98,1.52]$ & & - & \\
\hline Feng et al. 2015 & 42 & 45 & 38 & 45 & $2.3 \%$ & $1.11[0.95,1.28]$ & & - & \\
\hline Feng and Sun 2016 & 27 & 29 & 21 & 29 & $1.3 \%$ & $1.29[1.01,1.64]$ & & 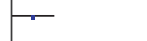 & \\
\hline Wu 2013 & 23 & 30 & 19 & 30 & $0.8 \%$ & $1.21[0.86,1.69]$ & & 5 & \\
\hline Chen and Lin 2016 & 55 & 59 & 48 & 60 & $2.3 \%$ & $1.17[1.01,1.35]$ & & - & \\
\hline Huang et al. 2013 & 27 & 30 & 23 & 30 & $1.4 \%$ & $1.17[0.93,1.48]$ & & - & \\
\hline Wang 2011 & 28 & 30 & 25 & 30 & $1.8 \%$ & $1.12[0.93,1.35]$ & & T- & \\
\hline Duan 2014 & 37 & 40 & 30 & 40 & $1.7 \%$ & $1.23[1.01,1.51]$ & & - & \\
\hline Bao and Zou 2015 & 25 & 30 & 8 & 30 & $0.0 \%$ & $3.13[1.69,5.78]$ & & & \\
\hline Wang and Yang 2013 & 45 & 45 & 40 & 45 & $2.8 \%$ & $1.12[1.01,1.25]$ & & - & \\
\hline Guo and Li 2016 & 36 & 40 & 28 & 40 & $1.4 \%$ & $1.29[1.02,1.61]$ & & - & \\
\hline Qin 2015 & 29 & 30 & 22 & 30 & $1.4 \%$ & $1.32[1.05,1.65]$ & & 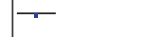 & \\
\hline Xie et al. 2011 & 37 & 65 & 20 & 65 & $0.0 \%$ & $1.85[1.21,2.82]$ & & & \\
\hline Zhao and Zhang 2012 & 90 & 94 & 76 & 92 & $2.9 \%$ & $1.16[1.05,1.28]$ & & 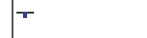 & \\
\hline Zhang 2014 & 44 & 50 & 33 & 46 & $1.6 \%$ & $1.23[1.00,1.51]$ & & - & \\
\hline Fang 2014 & 29 & 30 & 25 & 30 & $1.9 \%$ & $1.16[0.98,1.38]$ & & 5 & \\
\hline Yu and Hu 2011 & 34 & 40 & 24 & 38 & $1.1 \%$ & $1.35[1.02,1.77]$ & & 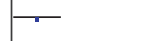 & \\
\hline Yin et al. 2011 & 15 & 18 & 15 & 20 & $0.9 \%$ & $1.11[0.80,1.54]$ & & - & \\
\hline Mao et al. 2015 & 38 & 40 & 37 & 40 & $2.7 \%$ & $1.03[0.92,1.15]$ & & + & \\
\hline Zhu et al. 2012 & 72 & 82 & 61 & 82 & $2.2 \%$ & $1.18[1.02,1.37]$ & & - & \\
\hline Total (95\% CI) & & 2420 & & 2389 & $100.0 \%$ & $1.17[1.13,1.21]$ & & 1 & \\
\hline \multirow{3}{*}{\multicolumn{7}{|c|}{$\begin{array}{l}\text { Heterogeneity: } \tau^{2}=0.01 ; \chi^{2}=129.46, \mathrm{df}=55(P<0.00001) ; I^{2}=58 \% \\
\text { Test for overall effect: } Z=9.08(P<0.00001)\end{array}$}} & & & \\
\hline & & & & & & & $\begin{array}{lll}0.1 & 0.2 & 0.5\end{array}$ & 12 & 5 \\
\hline & & & & & & & Control group & Acupuncture & re group \\
\hline
\end{tabular}

FIGURE 5: The forest diagram of the clinical efficacy rate. 


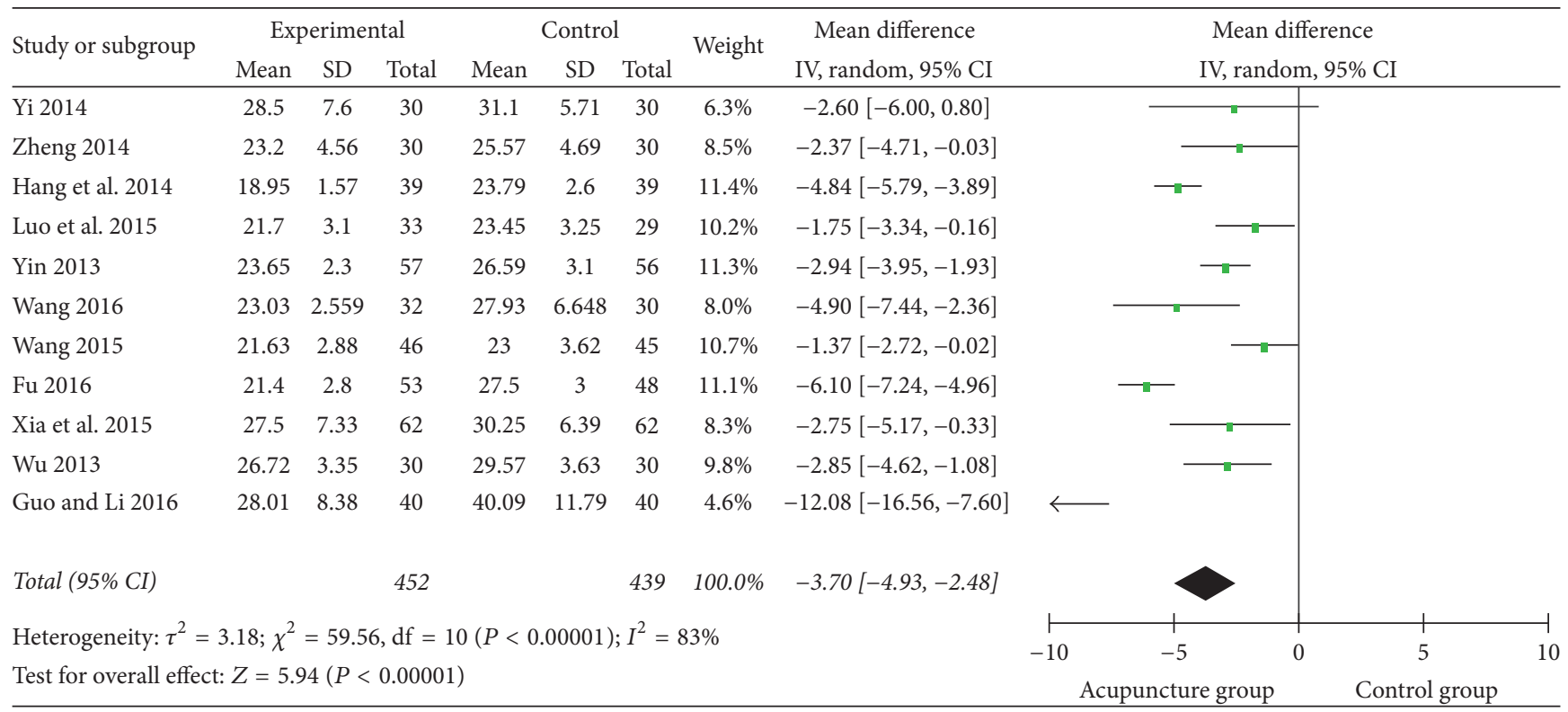

FIGURE 6: The forest diagram of SSA effective rate.

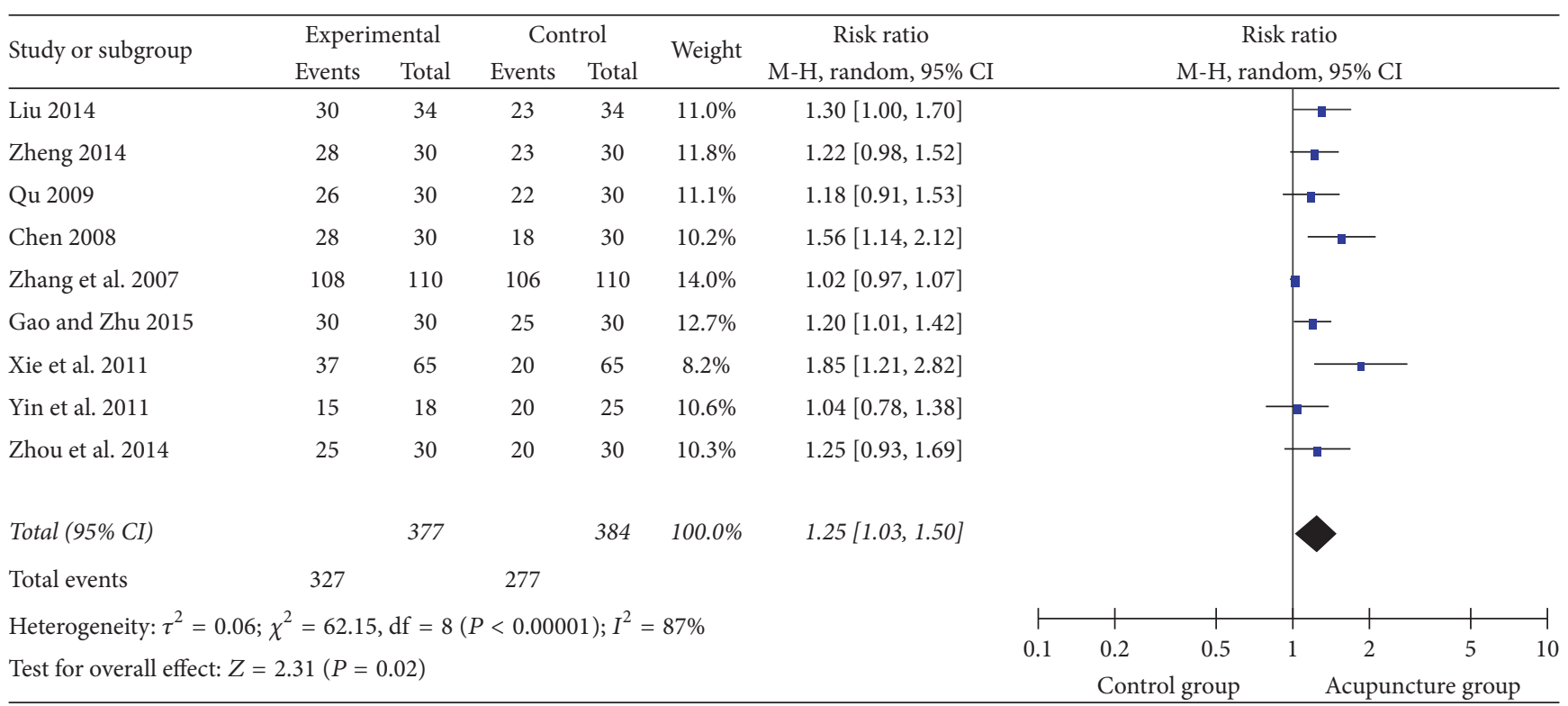

FIGURE 7: The forest diagram of WST effective rate.

On the outcome indicator of the dysphagia, most of the studies used the Watian Swallowing Test, SSA, Fujishima Rating Scale, and so on. Only 5 studies $[21,38,50,72$, 87] used the golden standard-videofluoroscopy (VFSFF) [91] as the assessment indicator. The Watian Swallowing Test was put forward by the Toshio Watian from Japan, which was used as preliminary screening for dysphagia. Meanwhile, it was dependent on the feeling of patients and susceptible to them, which made the inconsistencies with most results in clinical and laboratory inspection [92, 93]. However, it was classified clearly and simply to use.
So it was employed in many researches clinically [18, 21 , 23]. Therefore, the choice of evaluation criteria needs to be more rigorous and scientific in the clinical trial design. In order to increase the reliability, high level evaluators should be chosen to evaluate the efficacy for dysphagia simultaneously.

However, there were several limitations of this review. Some research used the acupuncture combined with other interventions on the basic of the control group. And it was easily mixed with the effect of the acupuncture. Therefore, for experiment group, acupuncture alone or combined with 


\begin{tabular}{|c|c|c|c|c|c|c|c|c|}
\hline \multirow{2}{*}{ Study or subgroup } & \multicolumn{3}{|c|}{ Experimental } & \multicolumn{3}{|c|}{ Control } & \multirow{2}{*}{ Weight } & \multirow{2}{*}{$\begin{array}{c}\text { Mean difference } \\
\text { IV, random, 95\% CI }\end{array}$} \\
\hline & Mean & SD & Total & Mean & SD & Total & & \\
\hline \multicolumn{9}{|l|}{ 2.2.1.28dWST } \\
\hline Wang 2015 & 2 & 1 & 46 & 3 & 1 & 45 & $7.1 \%$ & $-1.00[-1.41,-0.59$ \\
\hline Subtotal (95\% CI) & & & 46 & & & 45 & $7.1 \%$ & $-1.00[-1.41,-0.59$ \\
\hline
\end{tabular}

Heterogeneity: not applicable

Test for overall effect: $Z=4.77(P<0.00001)$

2.2.2. $20 d$ WST

Zhang and Yin 2012

Feng et al. 2015

Wang and Yang 2013

Qin 2015

$\begin{array}{lllll}1.6 & 1.06 & 62 & 2.2 & 1.15\end{array}$

$\begin{array}{lll}1.58 & 0.25 \quad 45\end{array}$

$\begin{array}{ll}2.73 & 0.22\end{array}$

$\begin{array}{lllll}1.79 & 0.61 & 45 & 2.9 & 0.24\end{array}$

$8.49 \quad 1.52 \quad 30$

6.131 .94

182

$56 \quad 7.1 \%$

$-0.60[-1.00,-0.20]$

Subtotal (95\% CI)

$0.00001) ; I^{2}=95 \%$

Heterogeneity: $\tau^{2}=0.30 ; \chi^{2}=66.03, \mathrm{df}=$
Test for overall effect: $Z=1.33(P=0.18)$

\subsection{3. $24 d$ WST}

Gao et al. 2014

Subtotal (95\% CI)

$2.71 \quad 0.84 \quad 52$

$\begin{array}{llll}3.01 & 0.89 & 49 & 7.4 \%\end{array}$

$-0.30[-0.64,0.04]$

Heterogeneity: not applicable

Test for overall effect: $Z=1.74(P=0.08)$

\subsection{4. $4 w W S T$}

\section{Song 2012}

Chen and Zhang 2016

Gao et al. 2016

Guo and Li 2016

Fang 2014

Subtotal (95\% CI)

$\begin{array}{ccccccc}1.56 & 0.82 & 30 & 2.06 & 0.87 & 30 & 7.0 \% \\ 1.33 & 0.661 & 30 & 1.83 & 0.874 & 30 & 7.2 \% \\ 1.4 & 1.11 & 40 & 2.38 & 0.97 & 40 & 6.9 \% \\ 1.24 & 0.29 & 40 & 2.97 & 0.21 & 40 & 8.0 \% \\ 1.71 & 1.59 & 30 & 5.12 & 2.07 & 30 & 4.8 \% \\ & & 170 & & & 170 & 33.8 \%\end{array}$

$-0.50[-0.93,-0.07]$

$-0.50[-0.89,-0.11]$

$-0.98[-1.44,-0.52]$

$-1.73[-1.84,-1.62]$

$-3.41[-4.34,-2.48]$

Heterogeneity: $\tau^{2}=0.64 ; \chi^{2}=81.93, \mathrm{df}=4(P<0.00001) ; I^{2}=95 \%$

$-1.34[-2.08,-0.60]$

Test for overall effect: $Z=3.57(P=0.0004)$

2.2.6. $1 w W S T$

Fang 2014

$5.03 \quad 2.31 \quad 30$

$\begin{array}{llll}5.34 & 1.89 \quad 30 \quad 4.2 \%\end{array}$

$-0.31[-1.38,0.76]$

Subtotal (95\% CI)

$4.2 \%$

$-0.31[-1.38,0.76]$

Heterogeneity: not applicable

Test for overall effect: $Z=0.57(P=0.57)$

\subsection{7. $60 d$ WST}

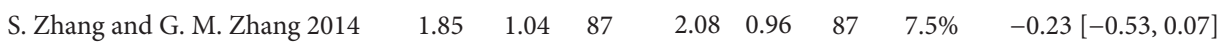

Subtotal (95\% CI)

Heterogeneity: not applicable

Test for overall effect: $Z=1.52(P=0.13)$

\subsection{8. $2 \mathrm{~m}$ WST}

Duan 2014

Subtotal (95\% CI)

$$
\begin{array}{llllllll}
2.4 & 0.4 & 40 & 3.2 & 0.8 & 40 & 7.6 \% & -0.80[-1.08,-0.52] \\
& 40 & & & 40 & 7.6 \% & -0.80[-1.08,-0.52]
\end{array}
$$

Heterogeneity: not applicable

Test for overall effect: $Z=5.66(P<0.00001)$

\subsection{9. $3 w W S T$ \\ Fang 2014}

Subtotal (95\% CI)

Heterogeneity: not applicable

Test for overall effect: $Z=2.66(P=0.008)$ $\begin{array}{lllll}3.78 & 1.88 & 30 & 5.14 & 2.08\end{array}$

$$
30
$$

$\begin{array}{ll}30 & 4.5 \% \\ 30 & 4.5 \%\end{array}$

$-1.36[-2.36,-0.36]$

$-1.36[-2.36,-0.36]$
Mean difference

IV, random, 95\% CI

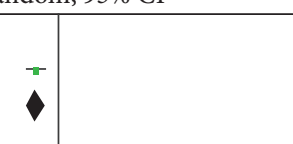

Total (95\% CI) $637 \quad 627 \quad 100.0 \% \quad-0.79[-1.11,-0.47]$

Heterogeneity: $\tau^{2}=0.33 ; \chi^{2}=284.98, \mathrm{df}=14(P<0.00001) ; I^{2}=95 \%$

Test for overall effect: $Z=4.82(P<0.00001)$

Test for subgroup differences: $\chi^{2}=21.47, \mathrm{df}=7(P=0.003), I^{2}=67.4 \%$

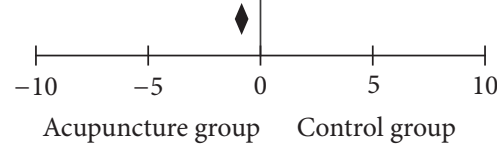

FIGURE 8: The forest diagram of WST subgroup analysis. 


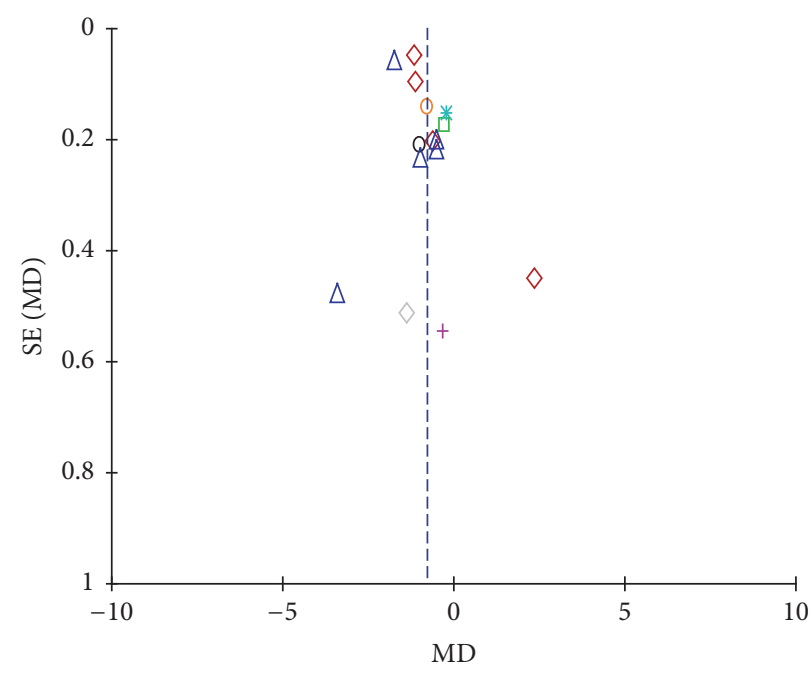

$\begin{array}{ll}\text { Subgroups } & \\ 0 \text { 28d WST } & +1 \mathrm{w} \mathrm{WST} \\ \diamond 20 \mathrm{~d} \text { WST } & * 60 \mathrm{~d} \text { WST } \\ \square 24 \mathrm{~d} \text { WST } & 02 \mathrm{mWST} \\ \triangle 4 \mathrm{w} \text { WST } & \diamond 3 \mathrm{wWST}\end{array}$

FIGURE 9: The funnel of WST subgroup analysis.

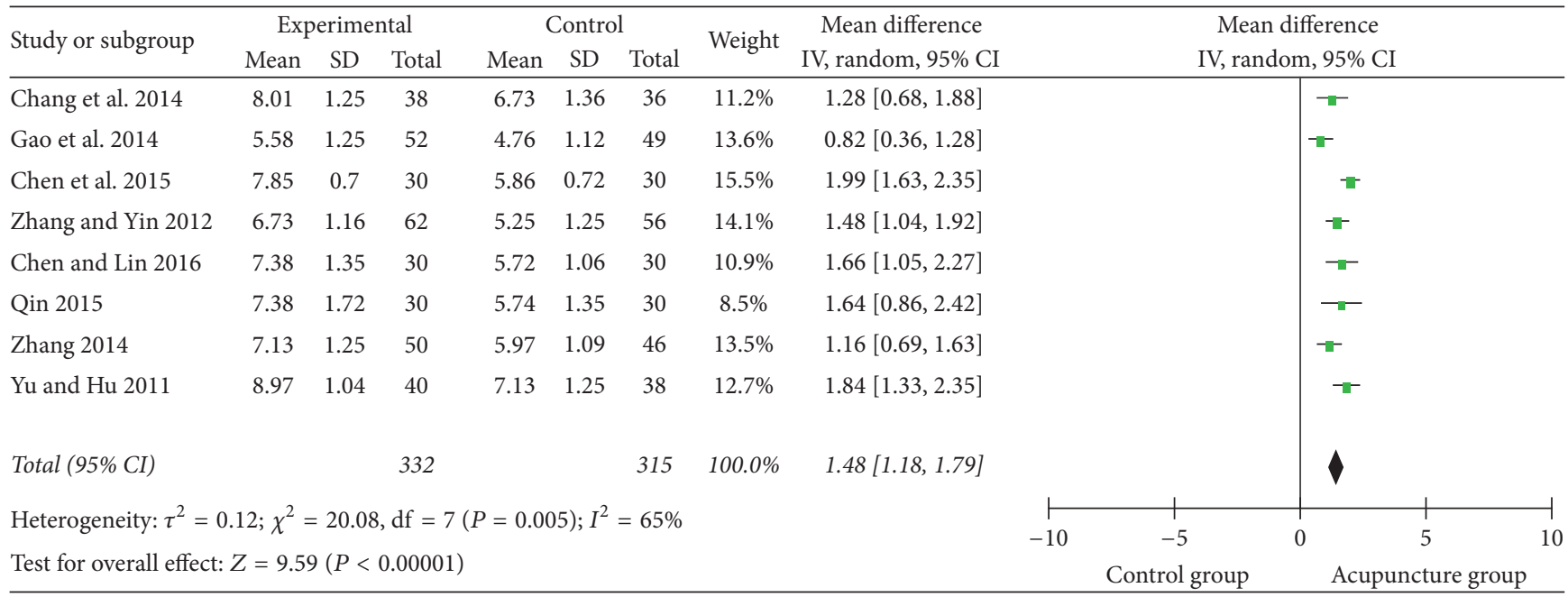

FIGURE 10: The forest diagram of swallowing function.

the interventions of the control group might increase the reliability.

Some studies [94, 95] showed that acupuncture seemed to be safe in the subacute phase of ischemic stroke and cardiac arrhythmia. Others [96] indicated that the safety of acupuncture needs further evidence. And some researches $[97,98]$ show that the occurrence of the adverse events during acupuncture was closely related to the competency of the practitioners and the safety system of acupuncture. However, in the process of literature retrieval, we found that most of the literatures included in this paper paid too much attention to the validity of acupuncture and ignored the influence of adverse event during acupuncture. Therefore, we should consider the security issues in the research design. The unfinished trials caused by the security issues should be reported perfectly according to international standard [99] to ensure the data's integrity.

\section{Conclusion}

In conclusion, acupuncture for dysphagia after stroke has therapeutic efficacy. And the acupuncture is safe and reliable within a certain range. More strict evaluation standard and high-quality RCT design are necessary for further exploration on the acupuncture for treatment of dysphagia after stroke. 


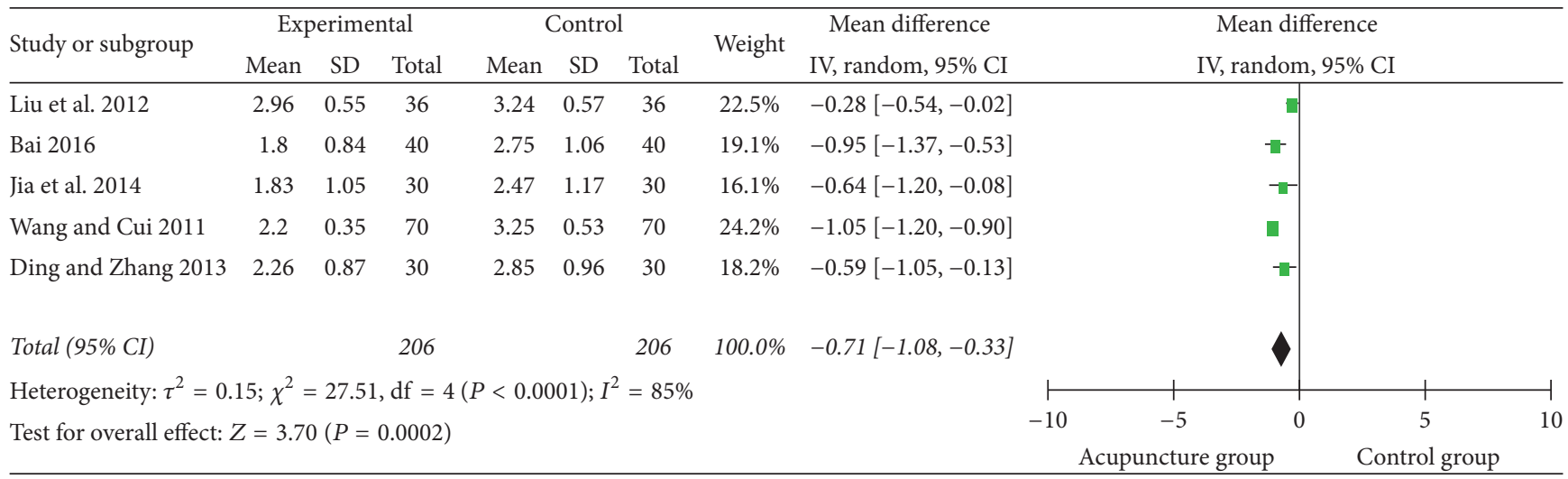

FIGURE 11: The forest diagram of swallowing disorder integral.

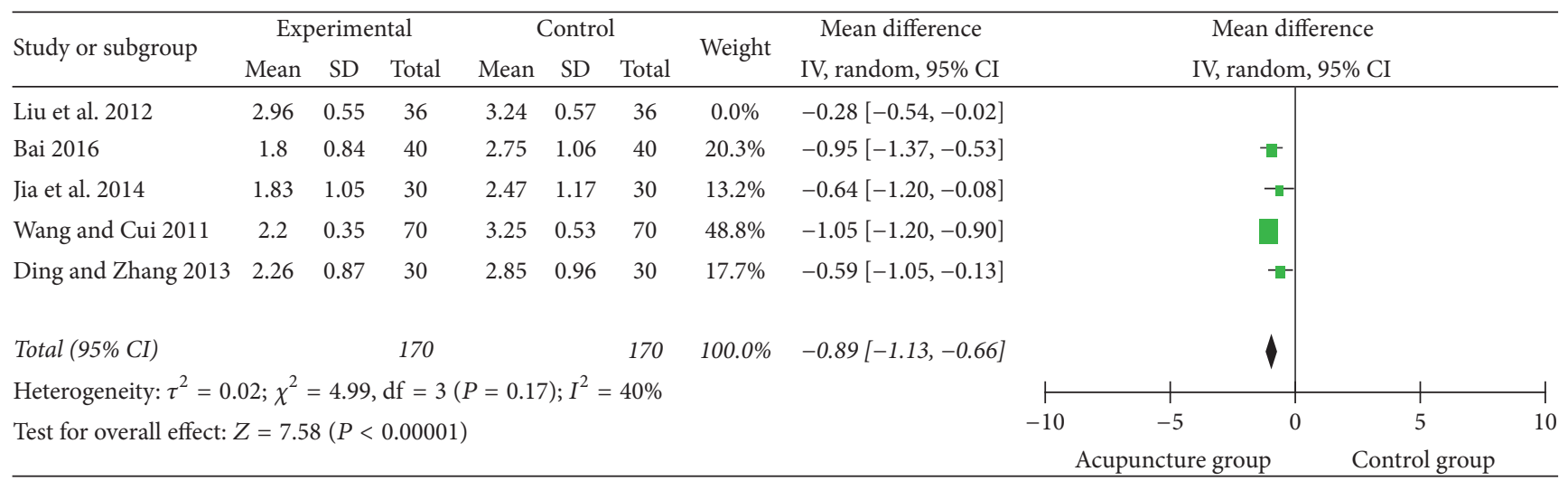

FIGURE 12: The forest diagram of SWAL-QOL.

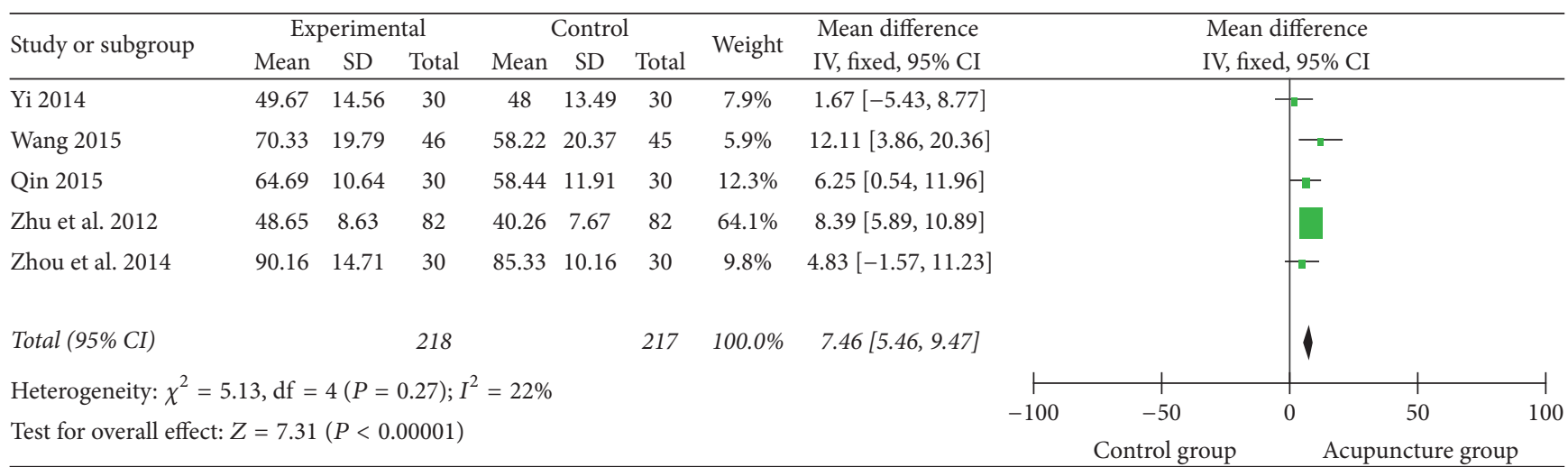

FIGURE 13: The forest diagram of ADL.

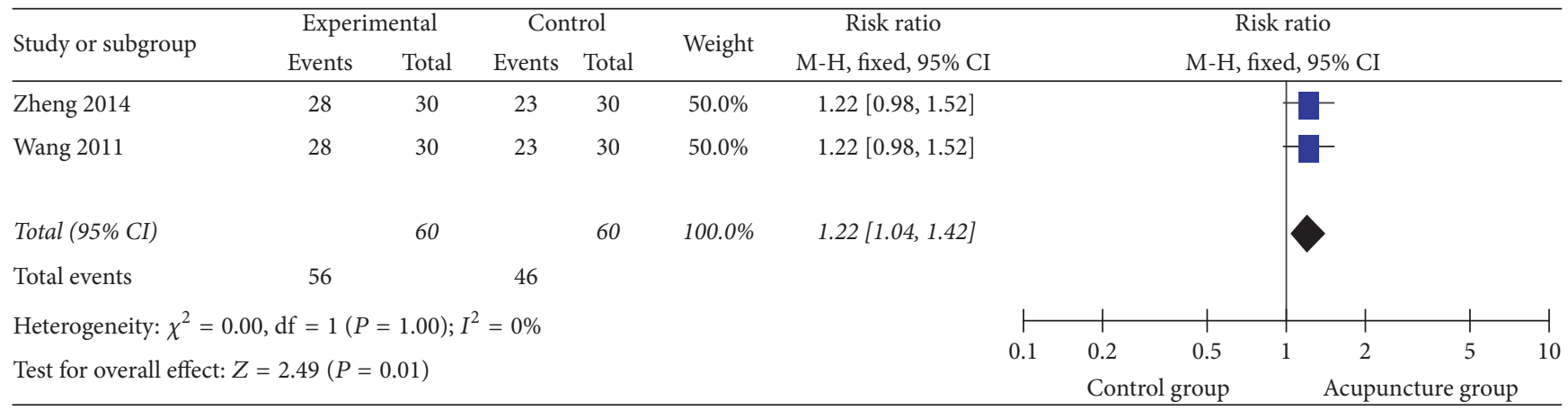




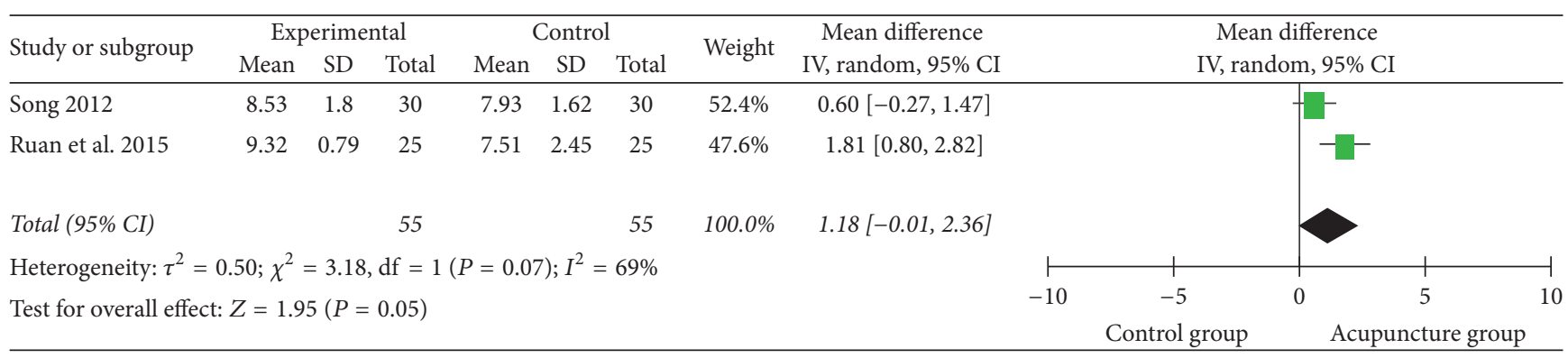

FIGURE 15: The forest diagram of IFRS.

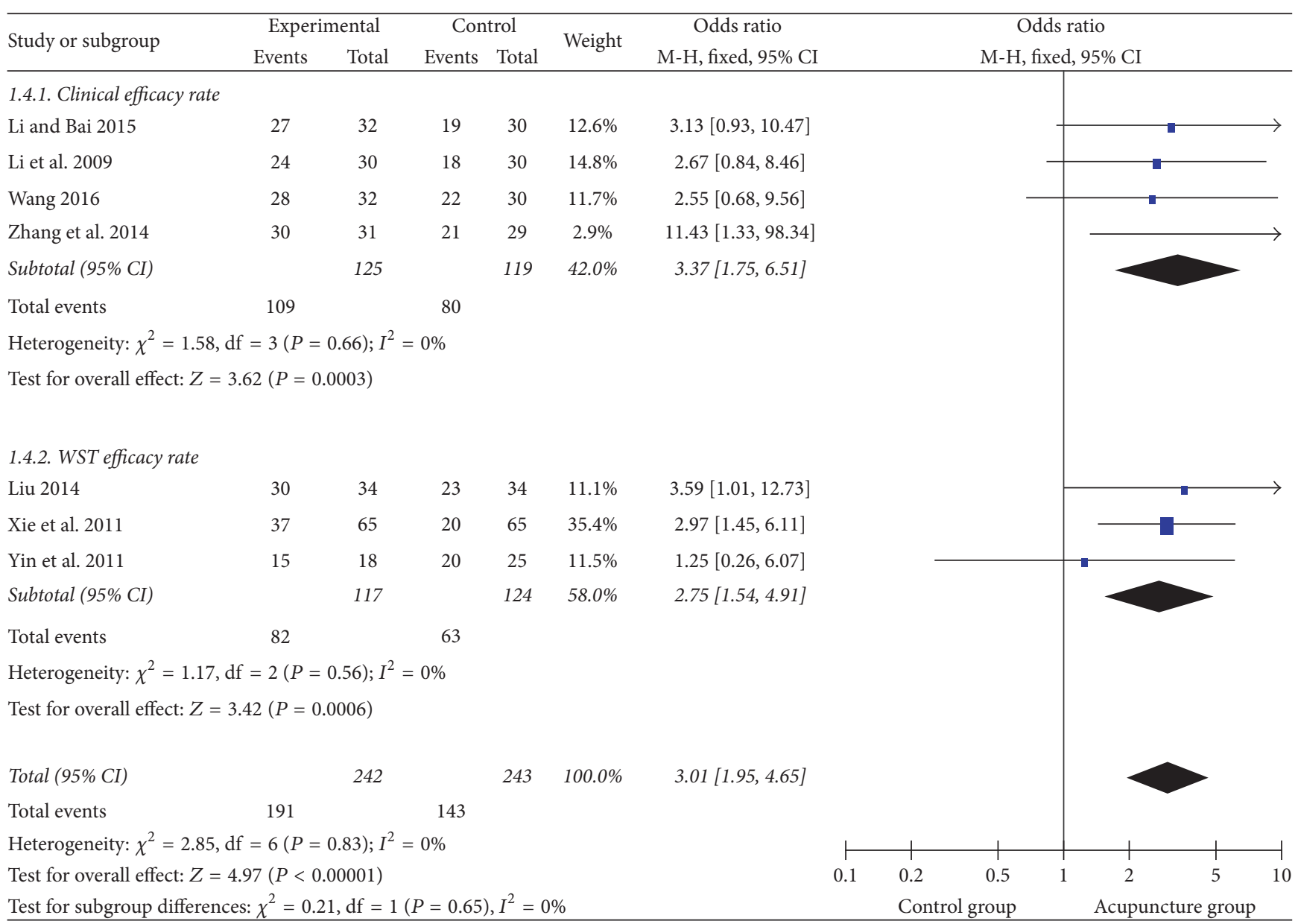

FIGURE 16: The forest diagram of single blind clinical efficacy rate.

\section{Abbreviations}

NIHSS: National Institutes of Health Stroke Scale

CT: $\quad$ Computerized tomographic scanning

MRI: Magnetic resonance imaging

SCI: $\quad$ Science Citation Index

CNKI: Chinese National Knowledge Infrastructure

CSJD: Chinese Scientific Journals Database

CBM: Chinese Biomedical Literature Database

CT7R: Caiteng 7 Rank

WST: Watian Swallowing Test

VFSS: Videofluoroscopy

ADL: Activity of Daily Life
IFRS: $\quad$ Ichiro Fujishima Rating Scale

WALQOL: Swallowing-Related Quality of Life.

\section{Disclosure}

Qiuping Ye is the first author. The funding agency was not involved in data collection, data analysis, data interpretation, or manuscript development.

\section{Conflicts of Interest}

The authors have no conflicts of interest to disclose. 


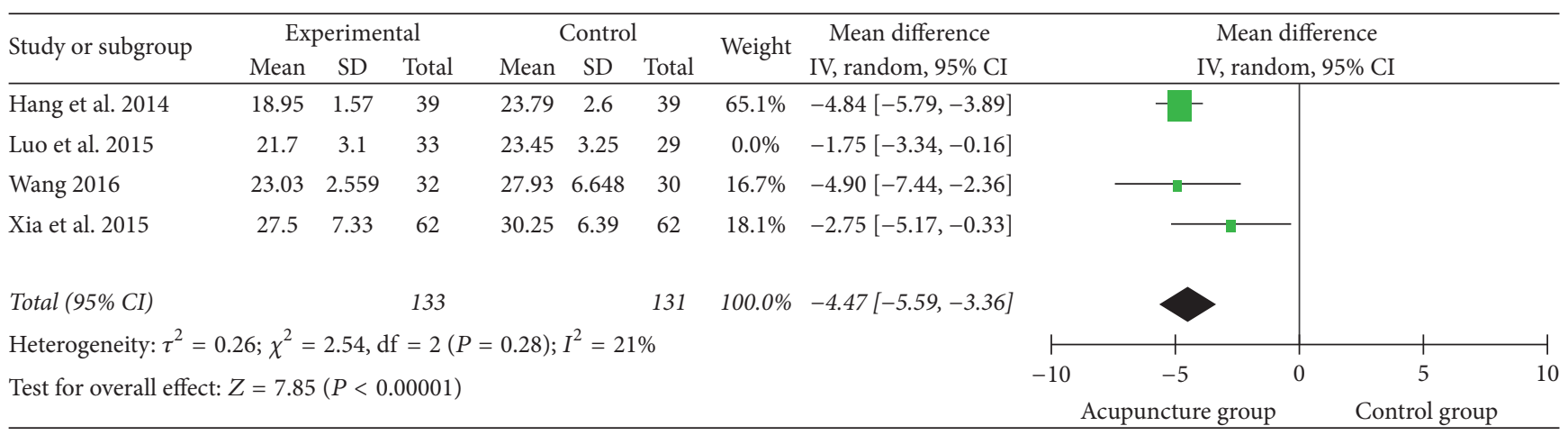

FIgURE 17: The forest diagram of single blind SSA.

\section{Acknowledgments}

The study was supported by the National Natural Science Foundation of China (no. 81373800) and The Key Project of National Natural Science Foundation of China (no. 81230088)

\section{References}

[1] M. Arnold, K. Liesirova, A. Broeg-Morvay et al., "Dysphagia in patients with brainstem stroke_ incidence and outcome," PLOS ONE, vol. 79, no. 2, pp. 170-175, 2000.

[2] D. G. Smithard, P. A. O'Neill, C. Park et al., "Complications and outcome after acute stroke: does dysphagia matter?” Stroke, vol. 27, no. 7, pp. 1200-1204, 1996.

[3] M. González-Fernández, L. Ottenstein, L. Atanelov, and A. B. Christian, "Dysphagia after stroke: an overview," Current Physical Medicine and Rehabilitation Reports, vol. 1, no. 3, pp. 187-196, 2013.

[4] H. Chang, Y. D. Kwon, and S. S. Yoon, "Use of acupuncture therapy as a supplement to conventional medical treatments for acute ischaemic stroke patients in an academic medical centre in Korea," Complementary Therapies in Medicine, vol. 19, no. 5, pp. 256-263, 2011.

[5] Z. Li F, "Research progress on acupuncture for dysphagia after stroke," Journal of liaoning iversity of traditional Chinese medicine, vol. 17, no. 8, pp. 210-212, 2015.

[6] J. He and Q. C. He, "The disscusion of clinical acupoint chosen rule and thorn moxibustion methods for acupuncture for dysphagia after stroke," Chinese Journal of Rehabilitation Medicince, vol. 23, no. 6, pp. 550-551, 2008.

[7] Z. W. Li, "The influence of acupuncture on the swallowing function of patients with apoplexy," China's Traditional Chinese Medicine Emergency, vol. 19, pp. 1609-01, 2010 (Croatian).

[8] A. Raglio, A. Zaliani, P. Baiardi et al., "Active music therapy approach for stroke patients in the post-acute rehabilitation," Neurological Sciences, vol. 38, no. 5, pp. 893-897, 2017.

[9] A. E. Arch, D. C. Weisman, S. Coca, K. V. Nystrom, C. R. Wira, and J. L. Schindler, "Erratum: Missed ischemic stroke diagnosis in the emergency department by emergency medicine and neurology services," Stroke, vol. 47, no. 3, pp. 668-673, 2016.

[10] Q. Sachiko and Q. Sun, PracTical Technique for Rehabilitation of Feeding and Swallowing Disorders [M], vol. 43, Chinese medical science and Technology Press, Beijing, China, 2000.
[11] J. B. Palmer, K. V. Kuhlemeier, D. C. Tippett, and C. Lynch, "A protocol for the videofluorographic swallowing study," Dysphagia, vol. 8, no. 3, pp. 209-214, 1993.

[12] C.-H. Zhang, J.-L. Bian, Z.-H. Meng et al., “Tongguan Liqiao acupuncture therapy improves dysphagia after brainstem stroke," Neural Regeneration Research, vol. 11, no. 2, pp. 285-291, 2016.

[13] Saito., "Eiichi the treatment of strategic about ingestion and dysphagia," J n. C G on the Mission of Medical, vol. 41, no. 6, pp. 404-408, 2004.

[14] B. Martin-Harris and B. Jones, "The videofluorographic swallowing study," Physical Medicine and Rehabilitation Clinics of North America, vol. 19, no. 4, pp. 769-785, 2008.

[15] C. Kuo, C. T. Allen, C. Huang, and C. Lee, "Murray secretion scale and fiberoptic endoscopic evaluation of swallowing in predicting aspiration in dysphagic patients," European Archives of Oto-Rhino-Laryngology, vol. 274, no. 6, pp. 2513-2519, 2017.

[16] P. Chung and J. Ishii, "jas. Cerebrovascular handicap of acute stage," Research of C, vol. 28, no. 5, pp. 415-421, 2000.

[17] J. Luo, Z. L. Gu, and Z. H. Xu, "The effect observation of 'Tiao Shen li Yan' acupuncture for dysphagia after stroke," Chinese Iournal of Physical and rehabilitation, vol. 37, no. 12, pp. 940942, 2015.

[18] W. Xia, C. Zheng, S. Zhu, and Z. Tang, "Does the addition of specific acupuncture to standard swallowing training improve outcomes in patients with dysphagia after stroke? a randomized controlled trial," A randomized controlled trial Clinical Rehabilitation, vol. 30, no. 3, pp. 237-246, 2015.

[19] Y. Xie, H. Liu, W. Zhou et al., "Effect of acupuncture on dysphagia of convalescent stroke patients," Chinese Journal of Integrated Traditional and Western Medicine, vol. 31, no. 6, pp. 736-740, 2011.

[20] Z. L. Yin, Z. X. Meng, and Y. J. Xie, "Swallowing training combined acupuncture and electrical stimulation treatment on stroke recovery excessie dysphagia," Chinese Iournal of Physical and rehabilitation, vol. 33, no. 12, pp. 916-919, 2011.

[21] R. Zhang, T. Li, and H. X. Chen, "Rev pharynx soup with acupuncture - rehabilitation treatment for dysphagia after ischemic stroke, a randomized controlled study," Xinjiang Journal of Traditional Chinese Medicine, vol. 32, no. 5, pp. 09-10, 2014.

[22] Q. L. Wang, Tongue Three-Needle Combined with Neuromuscular Electrical Stimulation Treat Dysphagia after Stroke A Clinical Research, Fujian University of Traditional Chinese Medicine, 2016. 
[23] B. D. Li and J. Bai, "Clinical observation of 62 cases of post-cerebral hemorrhagic dysphagia treated with cortexthroat-tongue root sequence acupuncture therapy," World Journal of Integrated Traditional and Western Medicine, vol. 10, no. 6, pp. 812-815, 2015.

[24] C. F. Liu, A study on the Effect of Acupuncture Combined with Rehabilitation for Stoke Patients with Swallowing Dysfunction in Acute Period, Chengdu University of Traditional Chinese Medicine, 2014.

[25] F. Hang, X. Fu, and T. Wang, "The effect of oral placement therapy combined with acupuncture of specific points on dysphagia after stroke," Chinese Journal of Rehabilitation Medicine, vol. 29, no. 12, pp. 1129-1133, 2014.

[26] H. X. Li, G. R. Qiu, and D. P. Liu, "Clinical observation of acupuncture combined with rehabilitation training on dysphagia after stroke," Journal of Shaanghai Acupuncture and moxibustion, vol. 28, no. 7, pp. 388-389, 2009.

[27] Z. Q. Zhu, G. G. Xu, and Y. L. Guo, "Effect of acupuncture combined with stroke unit model for dysphagia after stroke," Medical Journal of the Chinese People Armed Police Forces, vol. 02, no. 10, pp. 144-149, 2012.

[28] L. Chen and G. M. Zhang, "Efficacy observation acupuncture and comprehensive rehabilitation project for treatment of dysphagia after stroke," Journal of Emergency in Traditional Chinese Medicinevol.26, vol. no.6, pp. 1111-1113, 2016.

[29] C. Chen, L. X. Yuan, and G. M. Zhang, “The clinical curative research effect of comprehensive acupuncture and moxibustion therapy on swallowing disorder after stroke," Journal of Clinical Acupuncture and Moxibustion, vol. 30, no. 5, pp. 8-12, 2014.

[30] X. L. Wang, Clinical Research of Acupuncture Combined with Drug for Treatment of Dysphagia after Stroke, vol. 4, Guangzhou University of Chinese Medicine, 2013.

[31] Y. B. Duan, "The observation standard of clinical effect for acupuncture combined with medicine for treatment of dysphagia after cerebral hemorrhage," Cardiovascular Disease Journal of Integrated Traditional Chinese and Western Medicine, vol. 4, no. 12, pp. 28-29, 2014.

[32] Y. H. Bao and C. Zou, "Clinical observation of acupuncture combined with medicine for treatment of dysphagia due to pseudobulbar palsy after stroke," Zhejiang Chinese Medicine University, vol. 25, 62, no. 3, p. 62, 2015.

[33] C. F. Fan, H. Y. Jiang, and L. Z. Wu, "Clinical observation on acupuncture treatment of dysphagia after stroke," Shanghai Acupuncture and Moxibustion, vol. 26, no. 7, pp. 6-7, 2007.

[34] S. W. Feng, S. H. Cao, and S. J. Du, "Randomized controlled study of acupuncture combined with swallowing training for treatment of dysphagia after stroke," Chinese Acupuncture and Moxibustion, vol. 36, no. 4, pp. 437-450, 2016.

[35] S. R. Zhen, L. Li, and W. Li, "'Jieyuliqiao'-Clinical observation acupuncture for treatment of dysphagia after stroke," vol. 10, no. 12, p. 1462, 2012.

[36] L. Chang, P. L. He, and Z. Z. Zhou, "Observation on therapeutic effect of acupuncture combined with functional electrical stimulation on dysphagia after acute stroke," Chinese Acupuncture and Moxibustion, vol. 34, no. 8, pp. 7737-7740, 2014.

[37] P. Wu, F. R. Liang, and B. L. Yu, "Effect of different intervention time of acupuncture and rehabilitation training on dysphagia after stroke," Chinese Journal of Rehabilitation Theory and Practice, vol. 17, no. 8, pp. 733-736, 2011.

[38] R. Y. Zhang and Y. D. Yin, "Clinical observation on the treatment of dysphagia after cerebral infarction with Bushen acupuncture," Shanghai Journal of Acupuncture and Moxibustion, vol. 31, no. 9, pp. 637-639, 2012.

[39] Q. H. Chen, "Clinical observation on the effect of the treatment of dysphagia in stroke patients with the combination of the single point of Lianquan and the case of modified oral cavity," Chinese Medicine Modern Distance Education of China, vol. 6, no. 6, p. 649, 2008.

[40] Z. N. Mao, T. Y. He, and L. Y. Mao, "Clinical study on the treatment of dysphagia after stroke by Professor HeYou Tian - target - acupuncture therapy," annual meeting of Gansu Academy of traditional Chinese Medicine, pp. 89-93, 2015.

[41] Y. J. Guo and A. Y. Li, "Six spring needling combined with the emotional nursing on dysphagia after ischemic stroke- a randomized controlled," Journal of Clinical Acupuncture and Moxibustion, vol. 32, no. 5, pp. 43-46, 2016.

[42] S. Gao, H. Z. Huang, and S. F. Li, "Effect of swallowing function training combined with acupuncture on dysphagia after stroke," Hainan Medical Journal, vol. 27, no. 15, pp. 2531-2533, 2016.

[43] H. Bai, "Effect of swallowing therapy combined with acupuncture on dysphagia after stroke," Chinese Journal of Geriatric Care, vol. 14, no. 1, pp. 102-103, 2016.

[44] B. J. Song, China Academy of Chinese medical Science, China Academy of Chinese Medical Science, 2012.

[45] Z. Zhou, Y. L. Zhang, and H. Yuan, "The clinical observation of 60 cases of scalp and body acupuncture treatment for dysphagia after stroke," Lishizhen Medicine and Materia Medica Research, vol. 24, no. 9, pp. 2160-2162, 2014.

[46] C. Liu, "Therapeutic effect of acupuncture combined with swallowing training on dysphagia after stroke," Medical Recapitulate, vol. 10, no. 11, pp. 2095-2096, 2014.

[47] B. D. Li, J. Bai, and W. B. Gao, "Effect of neck acupuncture combined with swallowing training on pharyngeal phase of dysphagia after stroke," Chinese Journal of Physical Medicine and Rehabilitation, vol. 33, no. 1, pp. 31-32, 2013.

[48] X. Wang, "30 cases of scalp acupuncture combined with body acupuncture treatment of dysphagia after stroke," China's Naturopathy, vol. 19, no. 5, pp. 14-15, 2011.

[49] Q. L. Li and H. D. Zheng, "The clinical observation standard on Tongue three needles of Jinjin and Yuye point for treatment of dysphagia after stroke," Clinical Journal of Chinese Medicine, vol. 6, pp. 49-50, 2014.

[50] K. R. Gu, Evaluation of The Effect of Three Needles in The Treatment of Dysphagia after Stroke, Gungzhou University of Chinese Medicine, 2011.

[51] N. Gao, H. P. Ma, and X. Z. Zhang, "Clinical observation on treatment of dysphagia after stroke by Tongue acupuncture and Swallowing therapy instrument," Journal of Emergency in Traditional Chinese Medicine, vol. 23, no. 2, pp. 265-267, 2014.

[52] H. H. Chen, The Observation of Curative Effect of Tongue Acupuncture for Treatment of Dysphagia after Stroke, Zhejiang University of Chinese Medicine, 2016.

[53] C. L. Ruan, C. J. Zhuang, and Z. Q. Huang, "25 cases of dysphagia after stroke treated by Tongguanliqiao acupuncture," Fujian Journal of Traditional Chinese Medicine, vol. 41, no. 1, pp. 31-32, 2015.

[54] Q. Wang, "Clinical study of Tongguanliqiao acupuncture therapy for dysphagia after stroke," Shanghai Journal of Acupuncture and Moxibustion, vol. 34, no. 8, pp. 721-723, 2015.

[55] B. N. E. B. Li, L. J. Tian, T. G. L. S. E. A, H. L. Yuan, and H. M. La, "The application of the tongqiaoxingnao acupuncture for treatment of dysphagia patients after stroke," Journal of 
Emergency in Traditional Chinese Medicine, vol. 24, no. 8, pp. 2471-2473, 2015.

[56] J. H. Zhang, J. Y. Li, and Y. Zhao, "The clinical observation of Tongnaohuoluo acupuncture combined with swallowing training for treatment dysphagia after stroke," Journal of Liaoning University of Traditional Chinese Medicine, vol. 13, no. 12, pp. 188-191, 2011.

[57] F. Qu, The curative effect observation of Jin Three-needle combined with rehabilitation training for treatment of dysphagia after stroke, Guangzhou University of Chinese Medicine, 2009.

[58] X. M. Chen and H. J. Lin, "Xingnaokaiqiao acupuncture therapy for dysphagia after stroke in 59 cases," Jiangxi Journal of Traditional Chinese Medicine, vol. 8, no. 47, pp. 71-73, 2016.

[59] X. N. Gao and Q. X. Zhu, "Clinical observation of acupuncture treatment of four - pharyngeal ,for dysphagia after stroke of pseudobulbar palsy," Clinical Journal of Chinese Medicinevol, vol. 7, no. 1, pp. 54-57, 2015.

[60] D.-D. Liu, X. Tong, J.-Y. Kou, Y. Wei, T.-S. Yang, and L.-D. Qiao, "Influence of acupuncture on remodeling of swallowing functions for patients with pseudobulbar palsy after cerebral infarction," Journal of Acupuncture and Tuina Science, vol. 10, no. 1, pp. 44-48, 2012.

[61] S. Dong, H. B. Lv, and J. Q. Liu, "Clinical observation of acupuncture combined with swallowing function training on dysphagia (pharyngeal phase) after stroke," Chinese Journal of traditional Chinese Medicine, vol. 42, no. 2, pp. 129-131, 2014.

[62] Y. Zhang, "Effect of acupuncture combined with neuromuscular electrical stimulation on dysphagia after cerebral infarction," Journal of Sichuan of Traditional Chinese Medicine, vol. 32, no. 10, pp. 168-170, 2014.

[63] S. Li, J. S. E, and Y. Qin, "The effect of acupuncture combined with buccal muscle electrical stimulation on oral phase of dysphagia after stroke," Chinese Journal of Rehabilitation Theory and Practice, vol. 20, no. 3, pp. 221-223, 2014.

[64] Y. H. Wang and H. Y. Yang, "Study on the clinical curative effect of acupuncture on choke point combined with Kaiqiaoliyan stick and wallowing function training for dysphagia after stroke," Clinical Journal of Chinese Medicine, vol. 5, no. 9, pp. 41-43, 2013.

[65] N. Ding and S. Zhang, "Effect of nape acupuncture on swallowing function and TCD in patients with pseudobulbar palsy after ischemic stroke," Medicine Information, vol. 26, no. 5, 2013.

[66] Z. Fang, "The effect of acupuncture combined with Chinese medicine ice stimulation on swallowing function of patients with dysphagia after stroke," Journal of Traditional Chinese Medicine, vol. 55, no. 11, pp. 931-934, 2014.

[67] Y. Qin, Clinical study on acupuncture of eight extra-meridians based treatment of dysphagia after stroke, Chinese Medicine, Yunnan University of Traditional, 2015.

[68] S. Zhang and G. M. Zhang, "Treatment of 87 cases of dysphagia after stroke by acupuncture combined with swallowing rehabilitation training," Anhui University of Chinese Medicine, vol. 33, no. 5, pp. 56-59, 2014.

[69] B. B. Zhu and C. Y. Zhao, "Randomized parallel controlled study of acupuncture combined with swallowing training in the treatment of dysphagia after stroke," Journal of Practical Traditional Chinese Medicine, vol. 29, no. 11, pp. 152-153, 2001.

[70] R. T. Fu, "Treatment of 53 cases of dysphagia after stroke by acupuncture combined with routine treatment of cerebrovascular disease and rehabilitation therapy," Traditional Chinese Medicinal Research, vol. 29, no. 2, pp. 56-58, 2016.
[71] W. M. Zhang, P. Zheng, and W. Q. Zhang, "Standardization of acupuncture combined with rehabilitation training in the treatment of dysphagia after stroke," World Journal of Integrated Traditional and Western Medicine, vol. 2, no. 11, pp. 659-661, 2007.

[72] A. X. Wei and Y. L. An, "Clinical observation on 50 cases of dysphagia after stroke treated by acupuncture combined with swallowing function training," World Journal of Integrated Traditional and Western Medicine, vol. 7, no. 5, 2012.

[73] L. L. Yin, "Clinical study on acupuncture combined with rehabilitation therapy for 57 cases of dysphagia after stroke," Journal of Traditional Chinese Medicine, vol. 54, no. 9, pp. 766768, 2013.

[74] L. P. Huang, L. L. Sun, and X. X. Zhang, "Clinical observation of acupuncture combined with rehabilitation training on dysphagia after stroke," Shaanxi Journal of Traditional Chinese Medicine, vol. 32, no. 3, pp. 329-330, 2011.

[75] L. R. Chen, Q. Lin, and L. Lin, "Therapeutic effect of acupuncture combined with neuromuscular electrical stimulation on dysphagia after stroke: a report of 28 cases," Journal of Fujian University of TCM, vol. 21, no. 6, pp. 54-55, 2011.

[76] L. Wang and Y. Cui, "Clinical observation on 70 cases of dysphagia after stroke treated by acupuncture combined with pulse electrotherapy," Journal of Traditional Chinese Medicine, vol. 52, no. 24, pp. 2112-2114, 2011.

[77] A. Y. Li, "The curative effect observation of Quan point acupuncture combined with acupoint massage for treatment of dysphagia after stroke which was complicated by pulmonary infection," Journal of Emergency in Traditional Chinese Medicine, vol. 25, no. 9, pp. 1783-1785, 2016.

[78] C. X. Yi, The clinical efficacy observation of Rendu meridian acupoints combined with the stroke unit for treatment of dysphagia after stroke, Hunan University of Chinese Medicine, 2014.

[79] L. Jia, D. Liu, and J. Bai, "Effect analysis of four-choke acupuncture combined with rehabilitation therapy for dysphagia after stroke," Contemporary Medicine, vol. 20, no. 36, pp. 1-2, 2014.

[80] X. S. Huang, Q. Tian, and R. Y. Mo, "A randomized parallel controlled study of acupuncture for treatment of moderate to severe dysphagia in stroke patients," Journal of Practical Traditional Chinese Internal Medicine, vol. 27, no. 2, pp. 143-144, 2013.

[81] X. E. Feng and L. Sun, "Observation on therapeutic effect of acupuncture on dysphagia after stroke: a report of 30 cases," China Health Standard Management, vol. 7, pp. 149-151, 2016.

[82] Q. Chen, W. G. Xia, and B. G. Chen, "Clinical study on acupuncture treatment of dysphagia caused by pseudobulbar palsy after stroke," Nei Mongol Journal of Traditional Chinese Medicine, vol. 05, no. 11, pp. 118-119, 2015.

[83] W. X. Feng, P. Li, and Y. M. Min, "Acupuncture treatment of dysphagia after stroke: a report of 45 cases," Shaanxi Journal of Traditional Chinese Medicine, vol. 36, no. 1, pp. 91-92, 2015.

[84] Z. H. Yu and J. F. Hu, "78 Cases of Acupuncture Combined with Rehabilitation Training in The Treatment of Dysphagia after Stroke," in Proceedings of The 2011 Annual Meeting of The Chinese Society for Acupuncture And Moxibustion, pp. 55-58, 2011.

[85] Y. Z. Zhao and H. Zhang, "Observation on therapeutic effect of acupuncture combined with swallowing therapy on dysphagia after stroke," Shanxi Journal of Traditional Chinese Medicine, vol. 28, no. 5, pp. 29-30, 2012.

[86] W. J. Yu, M. X. Zhang, and C. M. Sun, "Acupuncture for dysphagia after stroke: a report of 30 cases," Journal of Clinical Acupuncture and Moxibustion, vol. 28, no. 12, pp. 21-23, 2012. 
[87] D. Zheng, Clinical Study of Scalp Acupuncture Combined with Rehabilitation Training for Treatment of Dysphagia after Stroke, Gungzhou University of Chinese Medicine, 2014.

[88] L. P. Wang and Y. Xie, "Systematic evaluation on acupuncture for treatment of dysphagia after stroke," Chinese Acupuncture, vol. 26, no. 2, pp. 141-146, 2006.

[89] D. Meng, Y. B. Shang, Y. F. Fu et al., "Clinical literature study of acupuncture and moxibustion in the treatment of post-stroke dysphagia based on meta analysis," Chinese Medicine Modern Distance Education of China, vol. 16, no. 64, pp. 148-153, 2016.

[90] Y.-B. Long and X.-P. Wu, "A meta-analysis of the efficacy of acupuncture in treating dysphagia in patients with a stroke," Acupuncture in Medicine, vol. 30, no. 4, pp. 291-297, 2012.

[91] M. M. B. Costa, "Videofluoroscopy: The gold standard exam for studying swallowing and its dysfunction," Arquivos de Gastroenterologia, vol. 47, no. 4, pp. 327-328, 2010.

[92] J. Zhang, Y.-J. Wang, and T. Cui, "Reliability and validity of nine rating scales for dysphagia following stroke," Chinese Journal of Clinical Rehabilitation, vol. 8, no. 7, pp. 1201-1203, 2004.

[93] J. W. Wu, X. Bi, and L. Song, "Value of applying water swallowing trst for patients with dysphagia after acute stroke," Journal of Shanghai Jiao Tong University(Medical Science, vol. 36, no. 7, pp. 1049-1053, 2016.

[94] S. Zhang, B. Wu, M. Liu et al., "Acupuncture efficacy on ischemic stroke recovery: multicenter randomized controlled trial in China," Stroke, vol. 46, no. 5, pp. 1301-1306, 2015.

[95] J. Liu, S. N. Li, L. Liu et al., "Conventional acupuncture for cardiac arrhythmia: A systematic review of randomized controlled trials," Chinese Journal of Integrative Medicine, pp. 19, 2017.

[96] Y. Cai, C. S. Zhang, S. Liu et al., "Electro-acupuncture for post-stroke spasticity: a systematic review and meta-analysis," Archives of Physical Medicine and Rehabilitation, 2017.

[97] H. J. Lee, Y. Kim, and W. Y. Kim, "Safety concerns with thoracoabdominal acupuncture: experience at a tertiary-care emergency department," Pain Medicine, 2017.

[98] Q. Y. Li, Y. Y. Liu, J. Zhang et al., "Analysis of the adverse reactions of acupuncture and acupuncture accidents," Chinese Acupuncture and Moxibustion, vol. 8, no. 31, pp. 0255-0930, 2011.

[99] D. Moher, K. F. Schulz, D. G. Altman, and L. Lepage, "The CONSORT statement: revised recommendations for improving the quality of reports of parallel-group randomized trials," Annals of Internal Medicine, vol. 134, no. 8, pp. 657-662, 2001. 


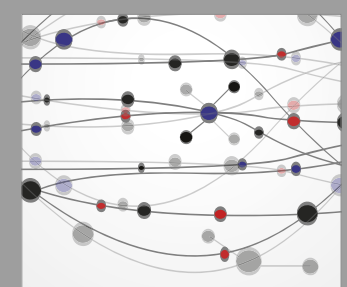

The Scientific World Journal
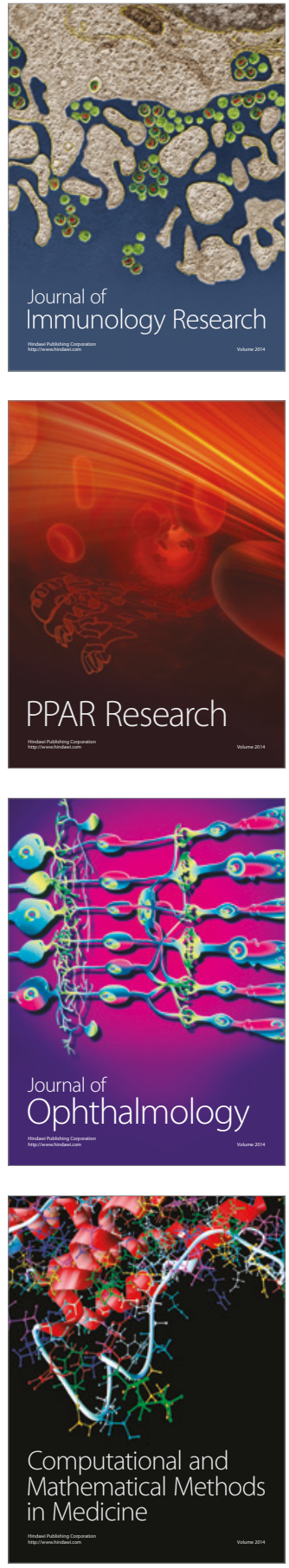

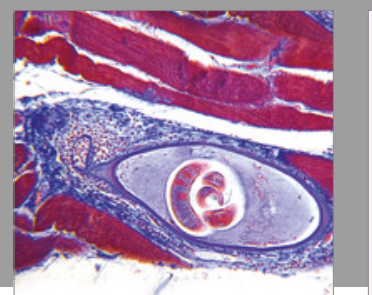

Gastroenterology Research and Practice
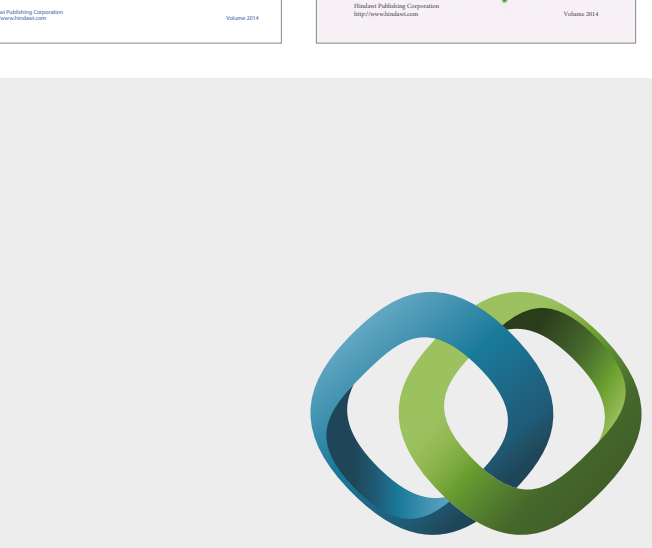

\section{Hindawi}

Submit your manuscripts at

https://www.hindawi.com
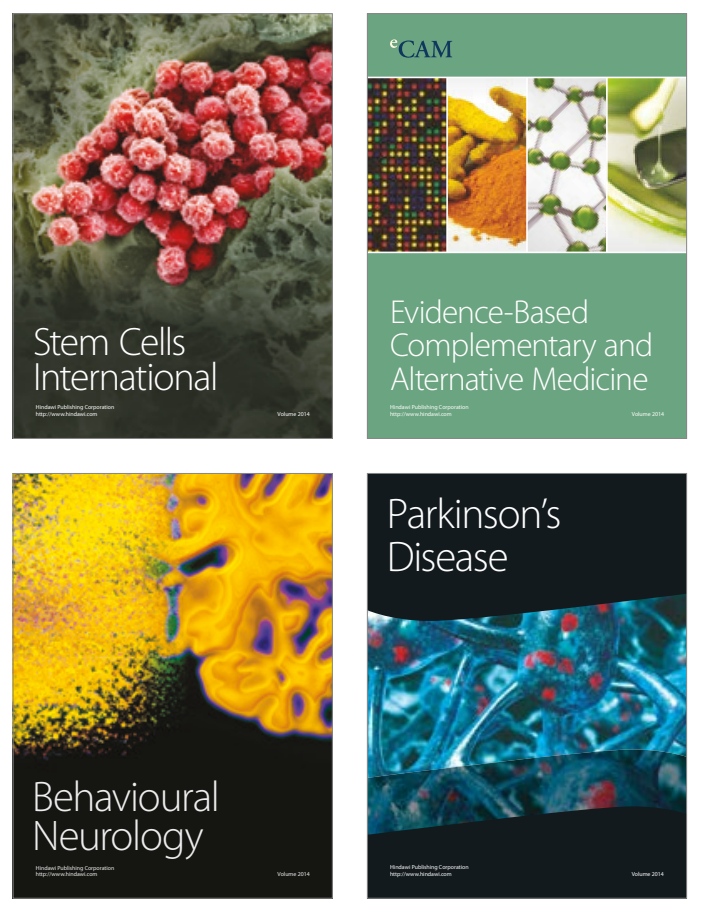
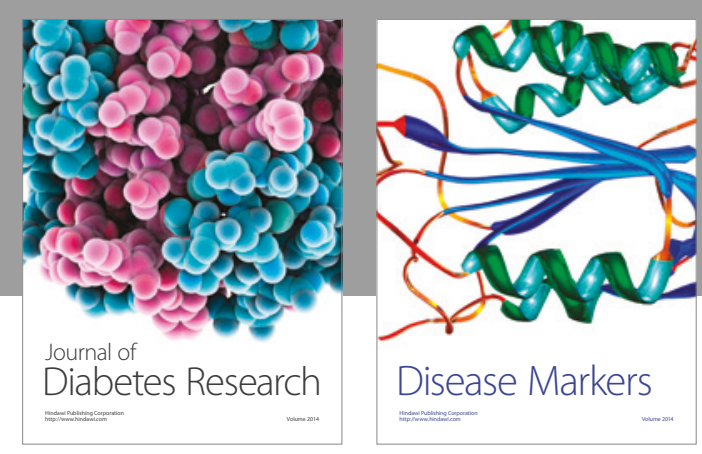

Disease Markers
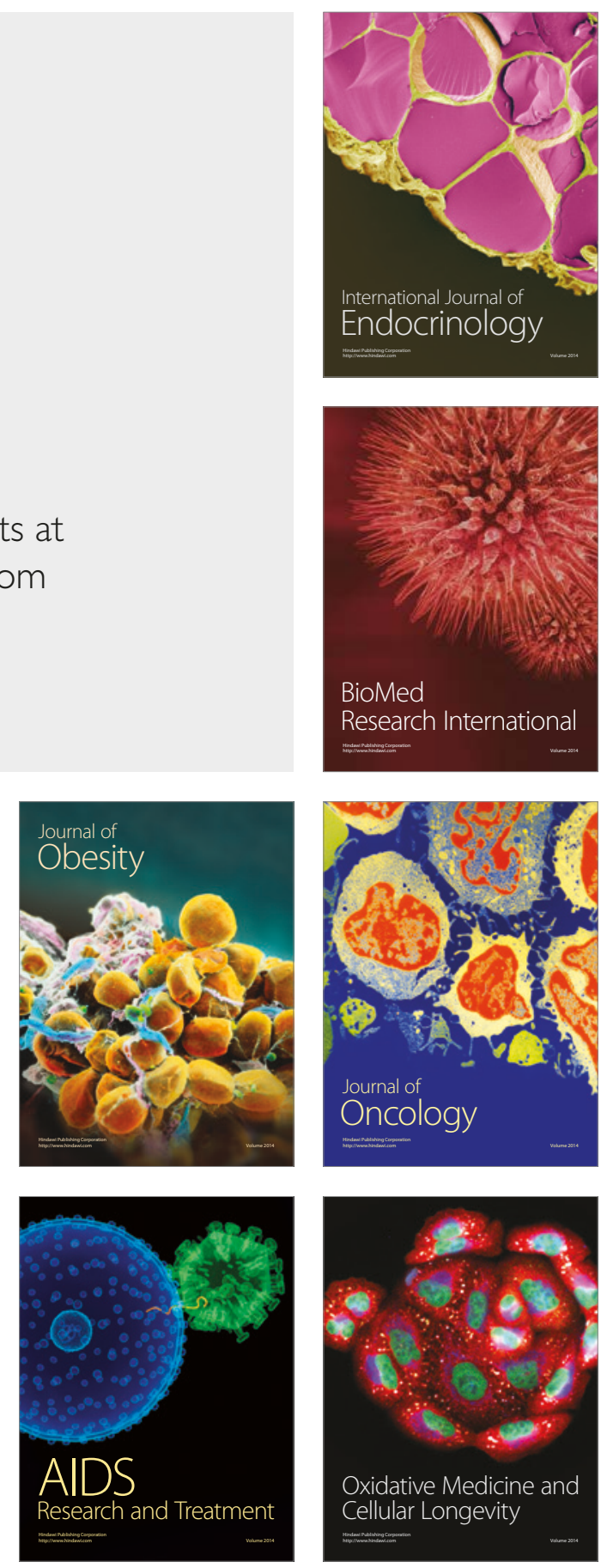